\title{
Thermally Distinct Ejecta Blankets From Martian Craters
}

\author{
BRUCE H. BETTS AND BRUCE C. MURRA Y
}

Division of Geological and Planetary Sciences, California Institute of Technology, Pasadena

\begin{abstract}
Utilizing the Termoskan data set of the Phobos ' 88 mission we have recognized a new feature on Mars: ejecta blanket distinct in the thermal infrared (EDITH). Virtually all of the more than 100 features discovered in the Termoskan data are located on the plains near Valles Marineris. EDITHs have a startlingly clear dependence upon terrains of Hesperian age, implying a spatial or temporal dependence on Hesperian terrains. Almost no thermally distinct ejecta blankets are associated with any of the thousands of craters within the data set that occur on the older Noachian units. EDITHs also do not appear on the portions of the younger Tharsis Amazonian units seen in the data The Hesperian terrain dependence cannot be explained by either atmospheric or impactor variations; Noachian and Hesperian terrains must have experienced identical atmospheric and impactor conditions during Hesperian times. Thermally distinct ejecta blankets therefore reflect target material differences and/or secondary modification processes. Not all lobate ejecta blankets are thermally distinct, but all EDITHs correlated with visibly discemible ejecta blankets are associated with lobate ejecta blankets. The boundaries of the thermally distinct areas usually follow closely the termini of the fluidized lobate ejecta blankets, even when the ejecta blankets show a high degree of sinuosity. Thus, the thermally distinct nature of EDITHs must be due to the primary ejecta formation process. The coupling of these thermal anomalies to morphology is unlike most sharp Martian inertia variations which are decoupled from observed surface morphology. Some thermally distinct ejecta blankets occur near otherwise similar craters that do not have thermally distinct ejecta blankets. Thus, wind patterns or locally available aeolian material cannot provide a single overall explanation for the observed variations. We compiled a data base of 110 EDITH and non-EDITH craters ranging in diameter from $4.2 \mathrm{~km}$ to $90.6 \mathrm{~km}$. There are almost no correlations within the data base other than occurrence on Hesperian terrains. We postulate that most of the observed EDITHs are due to excavation of thermally distinctive Noachian age material from beneath a relatively thin layer of younger, more consolidated Hesperian volcanic material. The plausibility of this theory is supported by much geological evidence for relatively thin near-surface Hesperian deposits overlying massive Noachian megabreccias on the EDITH-rich plains units. We suggest that absence of thermally distinct ejecta blankets on Noachian and Amazonian terrains is due to absences of distinctive near-surface layering. Thermally distinct ejecta blankets are excellent locations for future landers and remote sensing because of relatively dust free surface exposures of material excavated from depth.
\end{abstract}

\section{INTRODUCTION}

Ejecta blankets surround craters on many planetary and satellite surfaces. Lunar and Mercurian deposits have ballistically emplaced ejecta blankets. They appear coarse and disordered near the rim, then gradually thin and smooth out with increasing distance from the crater. Eventually, they blend into fields of secondary craters, rays, and the surrounding terrain [Shoemaker, 1962]. On Mars, in contrast, most craters larger than about $4 \mathrm{~km}$ in diameter have lobate ejecta blankets with rampart or convex termini. Many craters smaller than $4 \mathrm{~km}$ and a small percentage larger than $4 \mathrm{~km}$ have lunarlike ballistic ejecta morphology with radial lineations and a thin, irregular boundary [Strom et al., 1992]. At diameters larger than about 50 $\mathrm{km}$, radial lunarlike ejecta morphologies again dominate [Pike, 1980; Horner and Barlow, 1988]. A small percentage of craters have lobate blankets with superimposed radial striae. Many blankets are no longer visible due to erosion or blanketing by later deposits.

Formation of distinctive, relatively high relief, Martian lobate ejecta deposits with distinct termini was originally attributed to aeolian modification of lunarlike ejecta blankets [McCauley, 1973; Arvidson et al., 1976]. However, flow features evidenced more clearly in Viking images point toward formation by fluidized flow, such as shock-induced fluidization of volatiles in the surface materials [e.g., Carr et al., 1977; Mouginis-Mark,

Copyright 1993 by the American Geophysical Union.

Paper number 93JE00107. 0148-0227/93/93JE-00107\$05.00
1979; Barlow and Bradley, 1990]. Laboratory experiments involving impact into viscous targets have created ejecta blankets similar to those seen on Mars [Greeley et al., 1980; Gault and Greeley, 1978]. Laboratory experiments that vary atmospheric pressure and particle size have also reproduced some lobate crater morphologies [Schultz and Gault, 1979, 1984]. One of our motivations in studying Martian thermally distinct ejecta blankets in detail is to discern any additional clues to the origin of fluidized ejecta blankets.

Lunar eclipse and lunar nighttime observations show that at least the inner regions of some younger ejecta blankets are thermally distinct (usually warmer than surroundings) [Shorthill, 1972]. This is attributed to a greater preponderance of blocks. Newly recognized thermal anomalies associated with Martian ejecta blankets extend further and appear to be more complex in origin.

We have used the high spatial resolution of the thermal infrared/visible Termoskan instrument to carry out the first thermal study of Martian ejecta blankets. Approximately 100 craters within the Termoskan data have an ejecta blanket distinct in the thermal infrared (EDITH). To better understand these features, we have undertaken a threefold analysis: (1) a systematic examination of all Termoskan image data using highresolution image processing; (2) a formal study of the systematics of the data by compiling and analyzing a data base consisting of geographic, geologic, and morphologic parameters for a significant fraction of the EDITHs and nearby non-EDITHs (total ejecta blankets 110); and (3) qualitative and quantitative analyses of localized regions of interest. These methods, results, and conclusions are presented in the remaining portions of this paper. 


\section{MeTHod of OBSERVATION AND DATA ANAL YSIS}

In February and March 1989 the Termoskan instrument on board the Phobos ' 88 spacecraft of the USSR acquired a limited set of very high resolution simultaneous observations of the reflected solar flux and emitted thermal flux from Mars' equatorial region. These are the highest spatial resolution thermal data ever obtained for Mars (see Figure 1). The slightly overlapping panoramas cover a large portion of the equatorial region from $30^{\circ} \mathrm{S}$ latitude to $6^{\circ} \mathrm{N}$ latitude.

Termoskan was a two-channel optical-mechanical scanning radiometer with one visible channel $(0.5-1.0 \mathrm{~mm})$ and one thermal infrared channel (8.5-12.0 mm) [Selivanov et al., 1989; Murray et al., 1991]. The instrument was fixed to the spacecraft, pointing in the antisolar direction. As a consequence, all observations are at $0^{\circ}$ phase angle and only daytime observations were acquired.
Termoskan's resolution per pixel at nadir was $1.8 \mathrm{~km}$ for three of the four panoramas acquired and $300 \mathrm{~m}$ for the remaining panorama [Selivanov et al., 1989; Murray et al., 1991]. These resolutions per pixel are much better than those obtained by the Viking infrared thermal mapper (IRTM) (approximately 5 to 170 $\mathrm{km}$, with only a small fraction of the data near $5 \mathrm{~km} /$ pixel). Because of insufficient spatial resolution, studies of Viking IRTM data were unable to distinguish any Martian ejecta blankets as thermally distinct from their surroundings (P. R. Christensen, personal communication, 1991). Termoskan's spatial resolution is also better than that expected for Mars Observer's thermal emission spectrometer (TES) (3 km/pixel), although TES observations will provide spectral coverage and 2 p.m. and 2 a.m. local time coverage of the entire planet.

Thermal inertia, a bulk measure of the resistance of a unit surface area to changes in temperature, is commonly used to

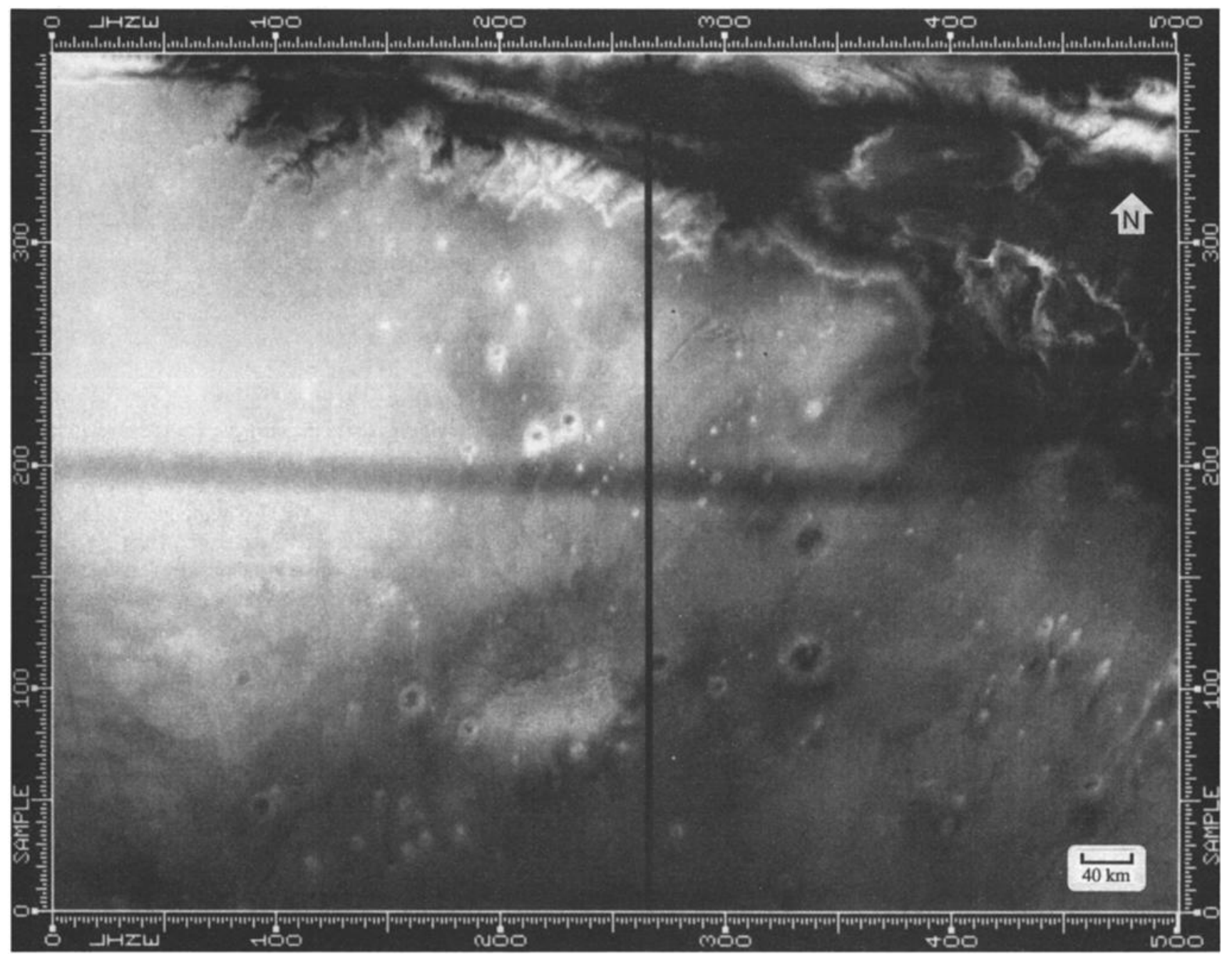

Fig. 1. (a) Image is from Temoskan's visible channel. (b) Image is from Termoskan's thermal infrared channel. They were obtained simultaneously. Time of day is near local noon. North is top in these and all other images in this paper. Part of Valles Marineris can be seen at the top of the images. In the themal image, the darker areas are cooler and lighter areas are wamer. Phase angle is approximately zero for all points. The dark east-west band is the thermal signature of the passage of the shadow of Phobos. Black vertical lines in the visible channel image represent missing lines of data. Note the thermally distinct ejecta deposits which appear as bright or dark rings surrounding craters in the thermal image (examples denoted by arrows). These deposits are up to $5 \mathrm{~K}$ wamer or cooler than their surroundings. White lines indicate geologic map boundaries. Geologic units and boundaries are from Witbeck et al. [1991] and Scott and Tanaka [1986] with some interpolation between the two. Units shown, from oldest, are Nplr, Noachian plateau ridged unit; Nf, Noachian fractured unit; Hr, Hesperian ridged plains material; Hsl, Hesperian Syria Planum fommation, Lower Member, and Hsu, Hesperian Syria Planum formation, Upper Member (see Table 2 for mone detail). Virtually all of the more than 100 EDITHs observed are situated on Hesperian age plains near Valles Marineris (e.g., Hr, Hsu, and Hf), but not on the older Noachian units (e.g., Nplr and Nf). EDITHs are almost exclusively associated with Hesperian age terrains throughout the data set. 


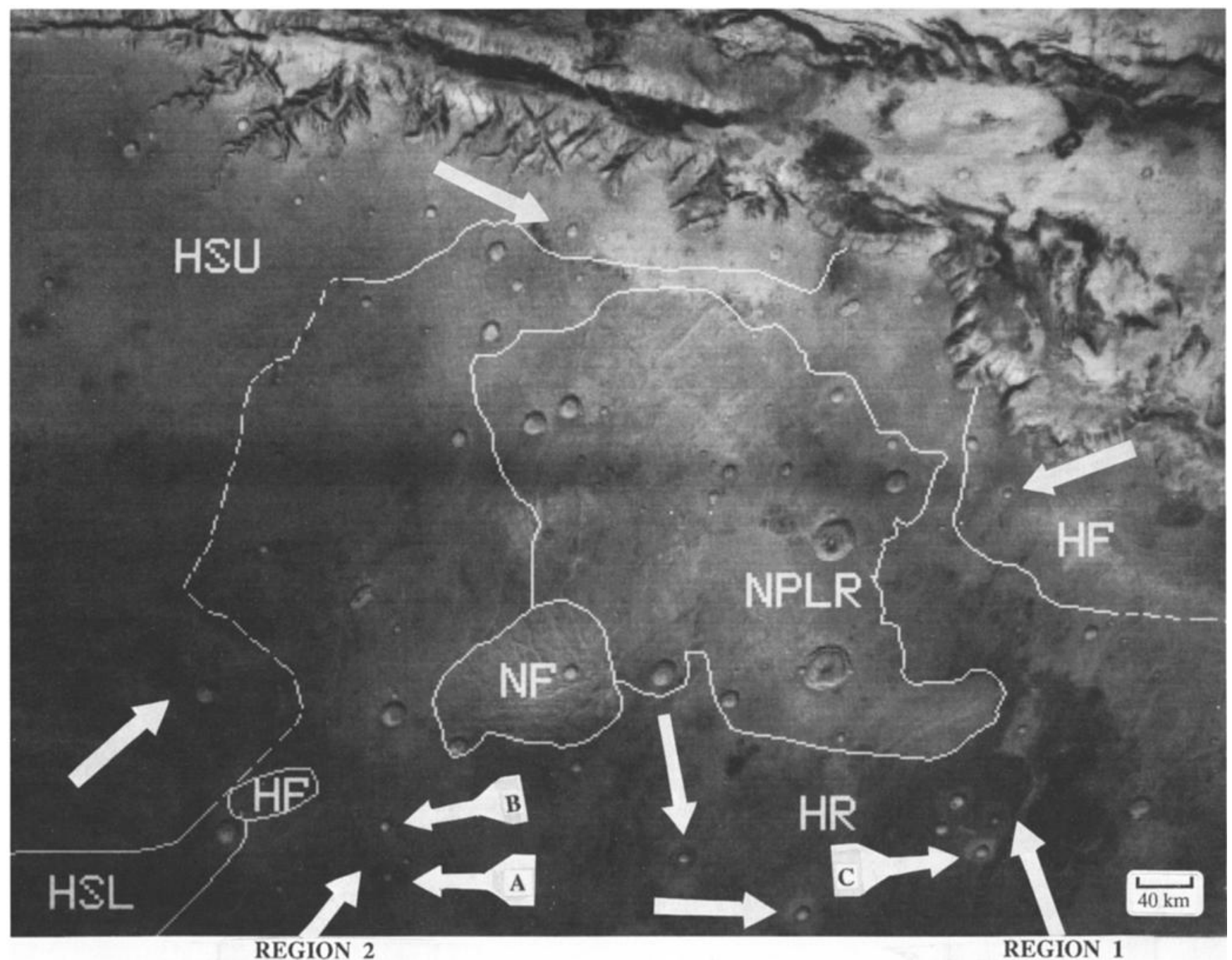

Fig. $1 b$

characterize the insulating properties of planetary surfaces. It is defined as $I=\left(k \rho c_{p}\right)^{1 / 2}$ where $k$ is the thermal conductivity, $\rho$ is the density, and $c_{p}$ is the specific heat. Low inertia materials exhibit the largest day-to-night temperature variation and the smallest thermal skin depths. Termoskan only obtained daytime observations, and generally only observed any given region once. Hence, accurate bolometric Bond albedo information would be necessary to determine absolute thermal inertias. Due to instrument limitations, atmospheric variations, and very limited phase angle viewing geometry, even approximate estimates of Bond albedo have thus far not yielded high confidence results [Murray et al., 1991; Betts, 1993]. Therefore, we use only relative thermal inertias and qualitative visible differences across craters in our analysis.

\section{PROPERTIES ASSOCIATED WITH INDIVIDUAL EDITHS}

On the Hesperian units where EDITHs are present, intensity profiles across different ejecta blankets vary greatly in both the thermal and visible channels (see Figures 2 and 3). Some of the blankets appear warmer than their surroundings, some appear cooler, and some are not thermally distinct. Some thermally distinct ejecta blankets appear distinct in the visible channel; however, others do not.

The boundaries of EDITHs often closely follow even very sinuous termini of lobate ejecta blankets (e.g., see Figures 4-7). Thus, the thermal anomalies are strongly associated with the blankets themselves. Those blankets that appear thermally distinct show no consistent pattern of radial thermal variation within each blanket. Many EDITHs are quite uniform in temperature across a given blanket.

Crater interiors often appear warm relative to ejecta and surroundings, as exemplified by the thermal profiles in Figures 2 and 3 as well as in Figure 1. In some cases this is probably due to low inertia material within the craters. However, in all but the flat floors of the largest craters one must consider the heating effects of slopes and of increased shadowing caused by crater topography. These effects are very difficult to separate from inertia and albedo effects without multiple observations. In this paper we will not comment further on the thermal signature of crater interiors. By contrast, slope and shadow history effects for ejecta blankets are much smaller due to the larger scales and smaller slopes involved.

In order to search for correlations and better understand EDITHs, we compiled a data base of craters and their ejecta which includes quantitative and qualitative information (see Table 1) [Betts, 1993]. Our data base includes 110 craters, most thermally distinct but some not. This set covers all craters larger than $8 \mathrm{~km}$ in diameter and most craters larger than $5 \mathrm{~km}$ 


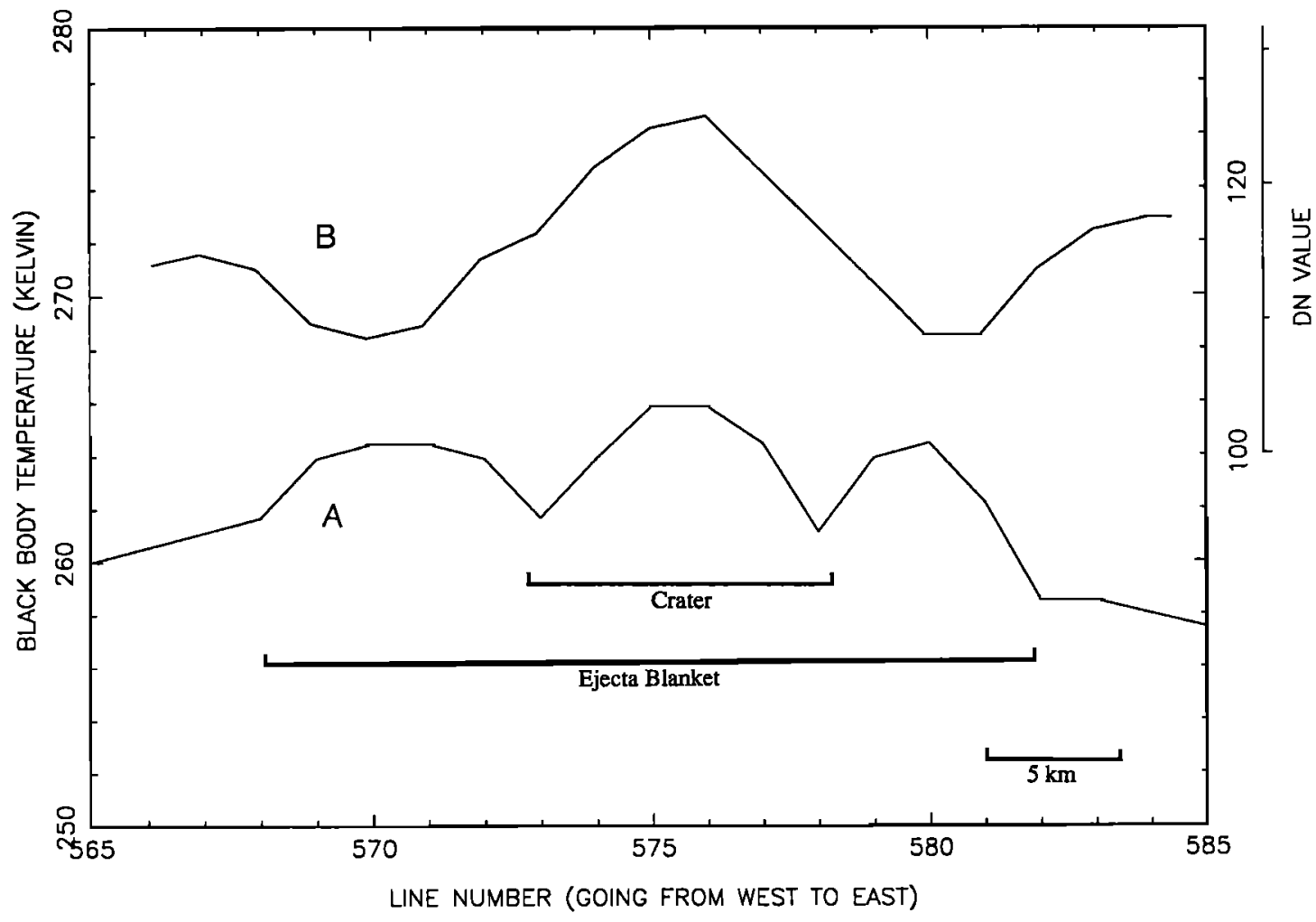

Fig. 2. West to east Termoskan infrared (curve A) and visible (curve B) profiles across fluidized ejecta blanket and $11.4 \mathrm{~km}$ crater located at $18.4^{\circ} \mathrm{S}, 74.0^{\circ} \mathrm{W}$ (crater 25 in Table 1; crater $\mathrm{C}$ in Figures 1 and 4). Note the three peaks in the temperature curve. The outer peaks correspond to the wam (relative to surroundings) ejecta blanket on either side of crater. The central peak corresponds to the warm crater interior. Note the inverse correlation between the temperature of the ejecta blanket and the visible signature, implying that in this case an albedo difference helps explain the wamer ejecta. This inverse correlation exists only in some crater profiles. The crater interior shows correlation between temperature and visible brightness, possibly indicating some degree of low inertia dust mantling in the crater interior.

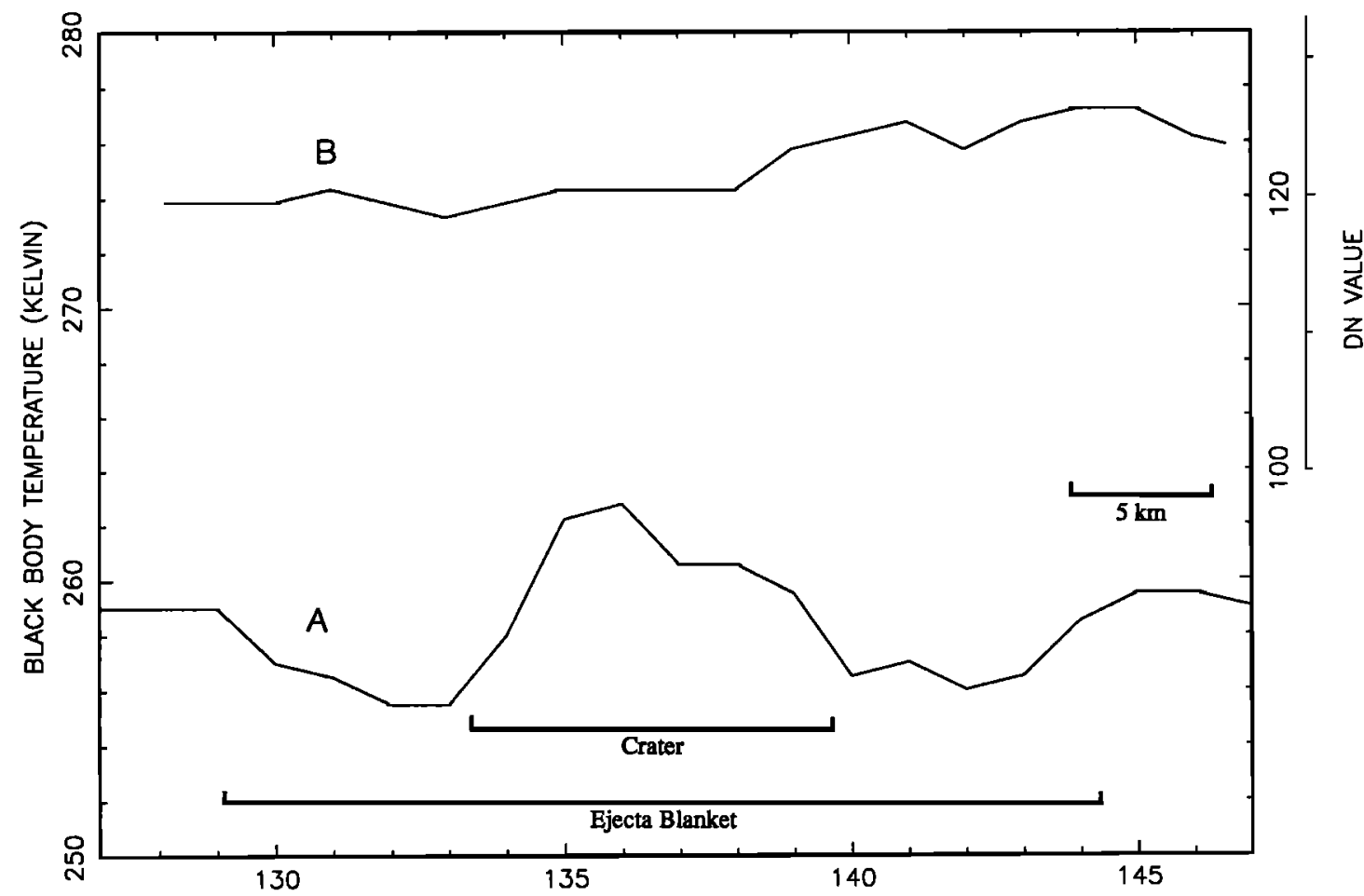

Fig. 3. West to east Termoskan infrared (curve A) and visible (curve B) profiles across fluidized ejecta blanket and $12.6 \mathrm{~km}$ crater located at $18.5^{\circ} \mathrm{S}, 88.7^{\circ} \mathrm{W}$ (crater 1 in Table 1 ; just off the western edge of Figure 1). This crater has an ejecta blanket that is cooler than the surroundings. Notice the two dips in the temperature curve that correspond to the fluidized ejecta blanket. Note that for this crater, the visible curve shows very little comelation to the temperature in either the ejecta blanket or crater interior. 

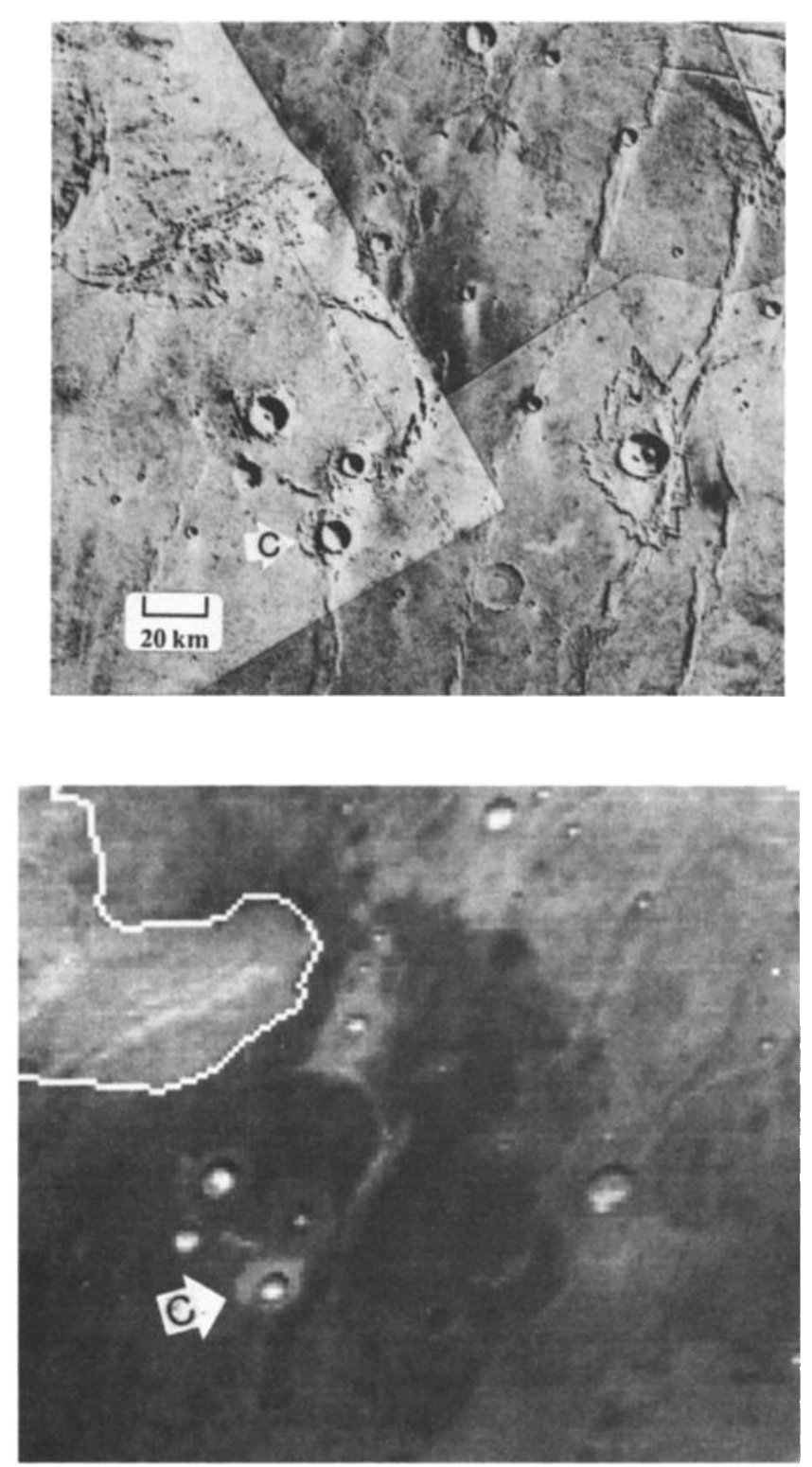

Fig. 4. Region 1 (seen also in lower right of Figure 1): Termoskan thermal image (bottom) and Viking visible photomosaic (top) of an interesting local region of study with four craters near the south rim of an old filled crater, and three craters to the northeast of the old crater. The craters seen outside the old filled crater exhibit ejecta blankets that are significantly warmer than the surroundings. These all are from the group of craters observed which have darker albedo than the surroundings. The craters inside the old filled crater have ejecta blankets which are much cooler than ejecta blankets outside the old filled crater, but still warmer than their surroundings. The only "ejecta blanket" that shows no temperature difference with the surroundings (the southwest crater) is the only crater for which no ejecta blanket can be seen in Viking images. Surviving portions of the old crater rim are also darker in the visible channel and wamer than the surrounding terrain. Also note that the southeast portion of the Noachian plateau ridged unit (Nplr), which appears to the northwest of the old filled crater, is also darker in the visible channel and wamner than surrounding areas. Crater $C$ is an excellent example of thermal boundaries matching ejecta boundaries. The wide thermal anomaly associated with the crater just $\mathrm{NE}$ of the large filled crater is a counterexample.

(smallest, $4.2 \mathrm{~km}$; largest, $90.6 \mathrm{~km}$ ) that are located in the northwest and southwest Coprates subquadrangles (MC-18NW and $\mathrm{MC}-18 \mathrm{SW}$ ) and fall within the Termoskan panoramas. Local time of day within this region varies from approximately
1130 to 1330 . The craters selected are located between $23.0^{\circ} \mathrm{S}$ and $8.0^{\circ} \mathrm{S}$ in latitude and $67.5^{\circ} \mathrm{W}$ to $90.0^{\circ} \mathrm{W}$ longitude. This area includes parts of Valles Marineris and several plains and ridged plains units of both Noachian and Hesperian age just south of Valles Marineris. This region was chosen for its many thermally distinct ejecta craters and its variety of geologic units. Many lobate ejecta craters are seen in this region in Viking images even down to subkilometer scales [Clifford and Duxbury, 1988].

For each crater in the data base, we have cataloged representative average temperatures for both the ejecta (EJET in Table 1) and the area surrounding the ejecta (SURT). Because the relative precision of Termoskan is approximately $0.5 \mathrm{~K}$ and
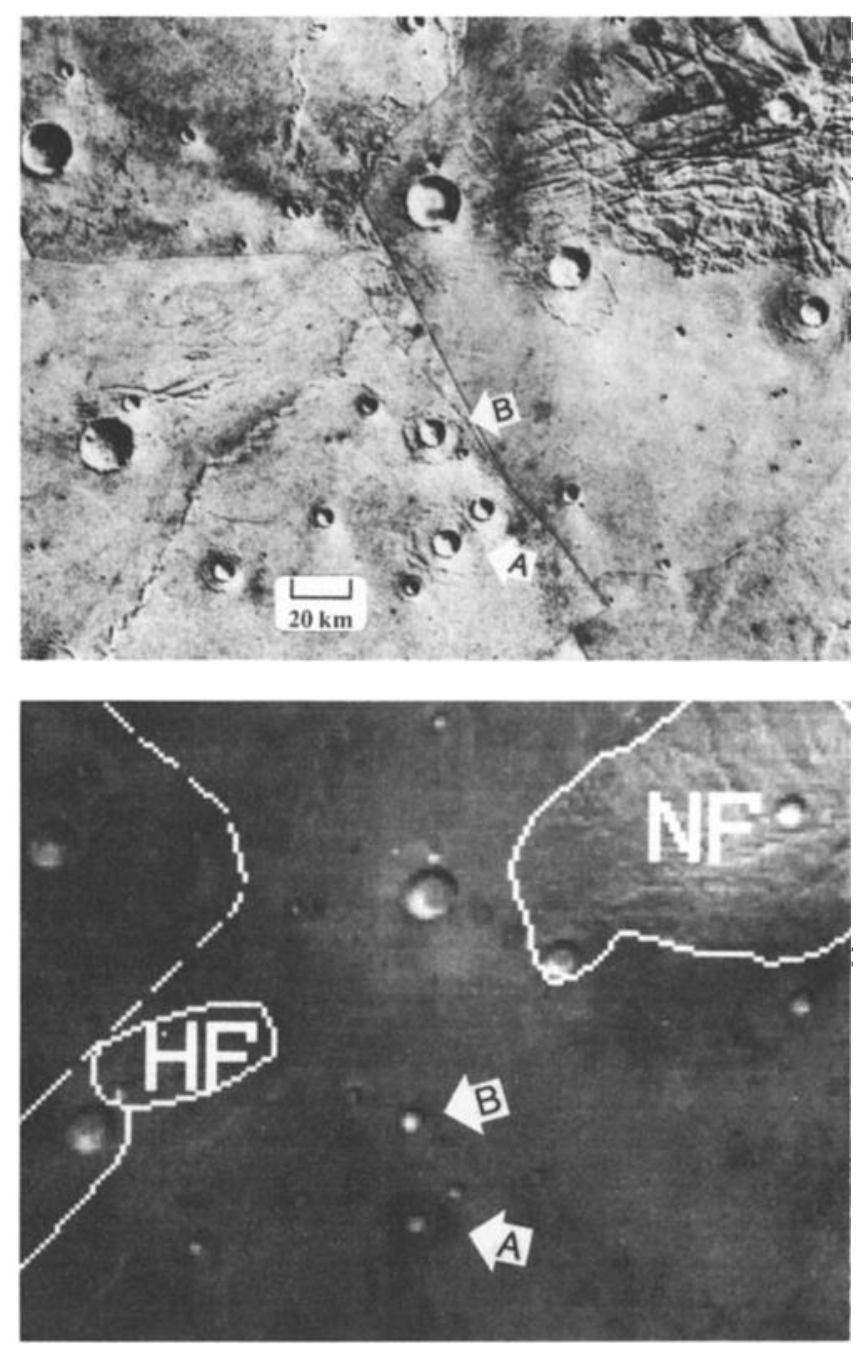

Fig. 5. Region 2 (seen also in lower middle of Figure 1): Termoskan thermal image (bottom) and Viking visible photomosaic (top) of several nearby craters, one with a thermally distinct ejecta blanket and the others without. In particular, notice the two largest craters, crater $\mathbf{A}$ and crater $\mathbf{B}$. Crater A is thermally distinct; crater B is not. They have similar fresh appearing single lobe fluidized ejecta blankets (N. G. Barlow, submitted report, 1987). Both craters are on the Hesperian ridged plains unit (Hr). Crater A $\left(18.54^{\circ} \mathrm{S}, 81.98^{\circ} \mathrm{W}\right.$; \#11 in Table 1) has a very thermally distinct ejecta blanket which is approximately $3.5 \mathrm{~K}$ warmer than its surroundings. It has a diameter of $11.6 \mathrm{~km}$ and a flat floor pristine interior (N. G. Barlow, submitted report, 1987). It is also distinct in the visible channel, being brighter than its surroundings. Crater $B\left(17.85^{\circ} \mathrm{S}, 82.07^{\circ} \mathrm{W} ; 12\right.$ in Table 1) does not have a thermally distinct ejecta blanket. It has a diameter of $8.6 \mathrm{~km}$ and a central peak (Pk) interior morphology. In the visible channel its ejecta blanket is not very distinct, if at all, from the surroundings. There are many smaller craters nearby and none of them appear thermally distinct. 

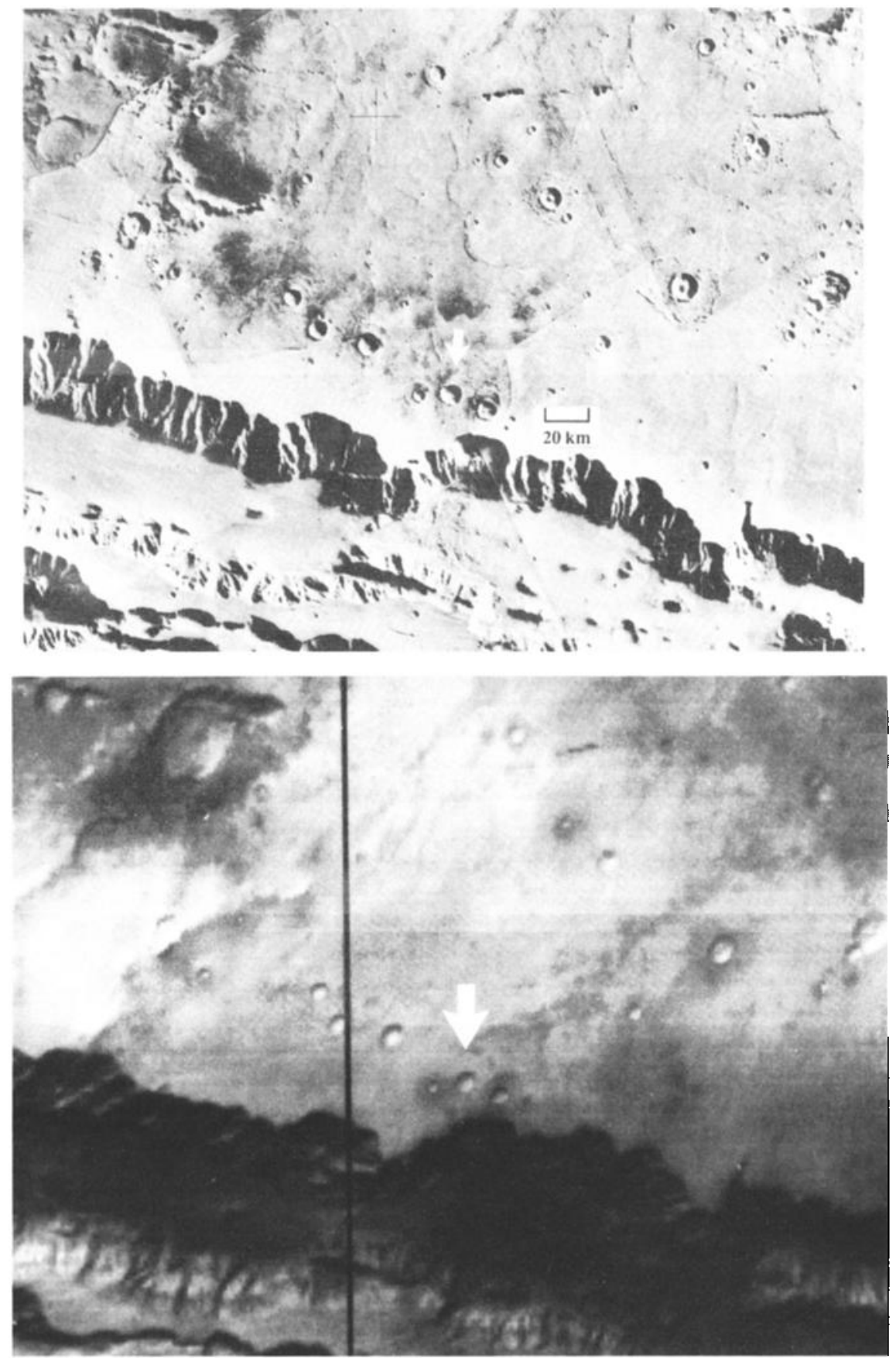

Fig. 6. Rogion 3: Termoskan thermal image (bottom) and Viking visible photomosaic (top) of three nearby almost aligned craters near the north rim of Valles Marineris (diameters $5.8 \mathrm{~km}, 10.5 \mathrm{~km}$, and $9.8 \mathrm{~km}$ ). They are centered approximately on $12.5^{\circ} \mathrm{S}, 59.3^{\circ} \mathrm{W}$. All three craters have single lobe ejecta morphologies. All occur on the Hpl 3 unit near a boundary with the Hr (Hesperian ridged plains) unit as determined by Wizbeck et al. [1991]. The largest (middle) crater is the only one of the three that does not have an EDITH. It also has the least fresh ejecta blanket based upon Viking images.

the absolute accuracy is better than $3 \mathrm{~K}$ [Murray et al., 1991], we have great confidence in relative Termoskan brightness temperatures. In Termoskan's less accurate visible channel, we similarly noted representative $d n$ (signal) values for both ejecta (EVIS) and the area surrounding the ejecta (SVIS).

We developed three descriptive thermal parameters, each expressing a somewhat different aspect of the ejecta blankets. First, we assigned a subjective "thermal freshness" parameter (TFR in Table 1) describing qualitatively how thermally distinct the ejecta appears relative to the surroundings. Second, we calculated temperature difference (DELT) between the ejecta blanket and the surrounding area using our representative average temperature values. Third, we calculated an approximate time of day corrected temperature for the ejecta alone (ETDS), thus giving a thermal parameter that does not depend upon the surroundings. To remove time of day effects to first order, we used a one-dimensional, homogeneous, thermal model of the Mars surface adapted from Clifford et al. [1987]. From each ejecta blanket temperature, we subtracted modelderived temperatures for average Mars conditions (inertia $6.5 \mathrm{x}$ $10^{-3} \mathrm{cal} \mathrm{cm}^{-2} \mathrm{~K}^{-1} \mathrm{~s}^{-1 / 2}$ and albedo 0.25 ) for the same time of day, season, and latitude. For comparison, we similarly subtracted 

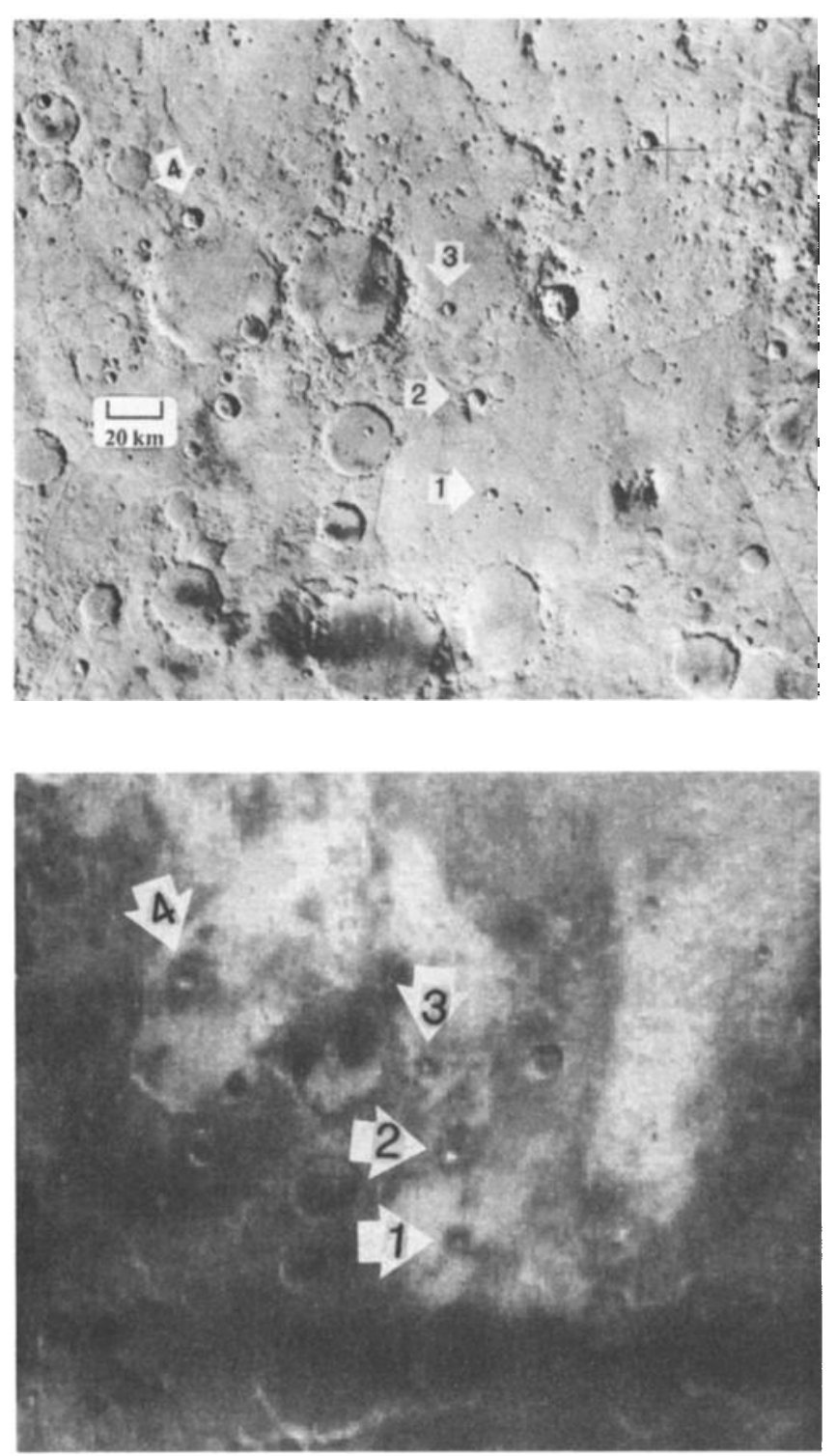

Fig. 7. Region 4: Termoskan thermal image (bottom) and Viking visible photomosaic (top) that include the four ciearly distinct EDITHs (designated by arrows) of panorama 4 . The four EDITHs are approximately centered upon $11.5^{\circ} \mathrm{S}, 197.0^{\circ} \mathrm{W}$ and are spaced over approximately $150 \mathrm{~km}$. Older highland materials appear to the south (bottom), and younger lowland material to the north. EDITHs all lie near the boundary on lowland terrains ( 1 and 2 on $\mathrm{Hpl}_{3}, 3$ on either Hpl 3 or Apk, 4 on Apk, using Greeley and Guest [1987]). Notice also the exposed crater rim of a buried crater near EDITH 2 (see text).

model temperatures from surrounding temperatures (STDS). We looked for correlations between each of the three thermal ejecta parameters (TFR, DELT, and ETDS) and the other parameters in our data base.

Our three descriptive thermal ejecta parameters showed no correlation with most of the parameters tested. Within the data base as a whole, there are no correlations between temperature difference, time of day corrected ejecta temperature, or thermal freshness with any of the following: crater diameter, ejecta morphology, interior morphology, existence of central pits, longitude, ratio of ejecta diameter to crater diameter, or time of day. The $1^{\circ} \times 1^{\circ}$ binned albedo, $2^{\circ} \times 2^{\circ}$ binned inertia, and $1^{\circ} \times$ $1^{\circ}$ binned elevation roughly correlate with time of day corrected ejecta temperature on the higher elevation Hsu (Syria Planum Formation, Upper Member) areas but not elsewhere (see Table 2 for unit descriptions). These relationships unique to Hsu are discussed below under section 4.

We present the following conclusions and observations based upon our systematic examination of individual EDITHs in the Termoskan data set.

1. On the plains where EDITHs occur, there cannot be uniform blanketing of depth greater than a very few centimeters by material younger than the craters. Otherwise, ejecta blankets would not be thermally distinct.

2. In regions with EDITHs there are varying degrees of ejecta blanket degradation at Viking Orbiter camera resolutions. Because there has not been significant blanketing in these regions (based upon conclusion \#1), this degradation is probably due to erosion, not deposition.

3. Some thermally distinct ejecta blankets appear distinct in the visible channel as well, implying albedo differences and probable surficial compositional differences with the surroundings. Many EDITHs are not visibly distinct, however, leaving textural differences (thermal inertia) as the cause.

4. The thermally distinct nature of EDITHs must be due to the primary ejecta formation process. Two related observations lead us to this conclusion. First, many thermally distinct areas are associated with areas surrounding craters. Second, many of the boundaries of these thermally distinct areas closely follow the termini of ejecta blankets. The dependence of the thermally distinct nature of EDITHs upon the primary ejecta formation process may be direct or indirect. Direct influence would result from either compositional or textural effects of the ejecta material itself. An example of indirect influence would be preferential secondary deposition of low-inertia material on the blankets due to increased roughness.

5. EDITHs are therefore strongly coupled with surface morphology, including those EDITHs that have different thermal inertia than their surroundings. This is significant because most sharp thermal inertia contrasts on Mars are decoupled from morphology.

6. Presence of ejecta blankets alone does not imply the presence of EDITHs. There are many visibly discernible ejecta blankets on Noachian, Hesperian, and Amazonian aged units that do not have EDITHs. At Viking camera resolutions, there are non-EDITH craters that look like EDITH craters. Also, they cover similar size ranges. Furthermore, existence of a lobate ejecta blanket does not imply the existence of an EDITH (only $50 \%$ of the lobate ejecta blankets on Hesperian terrains are thermally distinct). However, lobate morphology may be required for EDITHs. We cannot yet confirm this because of the absence of any other distinctive ejecta morphology on terrains where EDITHs were observed. Nevertheless, all EDITHs associated with discernible ejecta blankets are associated with fluidized, lobate ejecta blankets. Thirty percent of the craters classified by N. G. Barlow (Catalog of large Martian impact craters, submitted as NASA Contractor Report, 1987; hereinafter referred to as submitted report, 1987) as having non-discernible ejecta blankets have thermally distinct "ejecta blankets." Thus, these ejecta may or may not show lobate morphologies at higher resolution, and/or they may be partially eroded.

7. The absence of correlations between any of our three temperature parameters and ejecta morphology (single, double, or multiple lobes) implies that any physical differences between different fluidized ejecta morphologies are not capable of causing consistent thermal differences. 


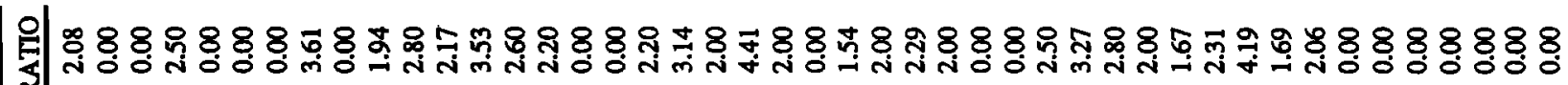
$\$$

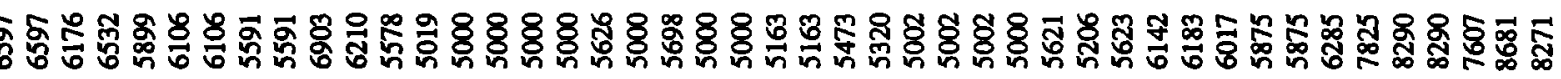

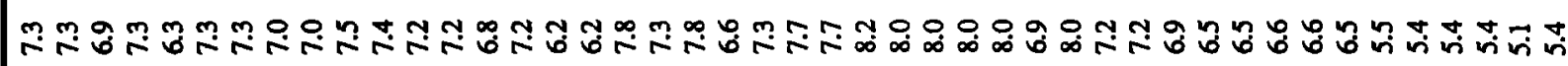

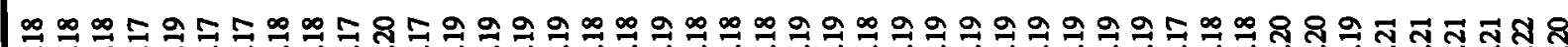

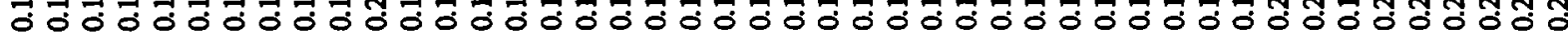

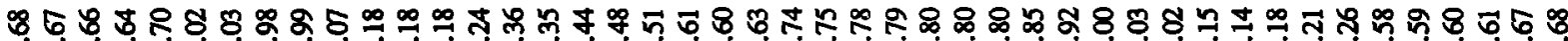
$\exists=\exists \Xi$ J

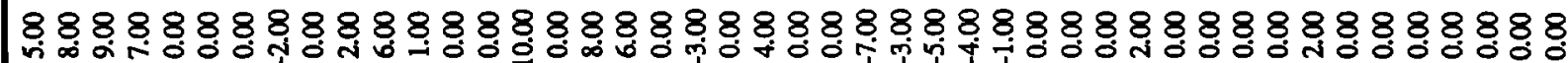

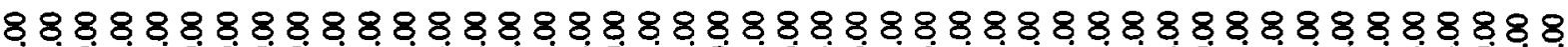

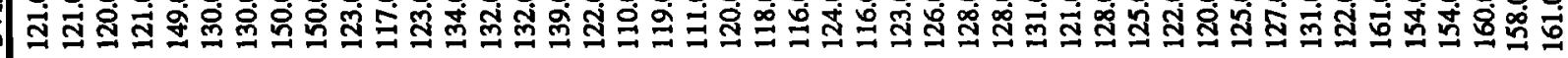

2 888888888888888888888888888888888888888888888

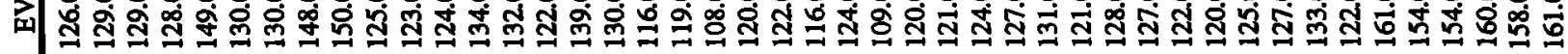

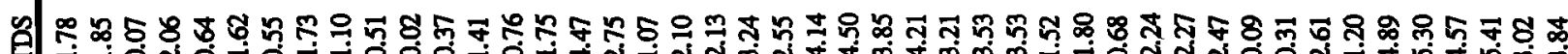
-

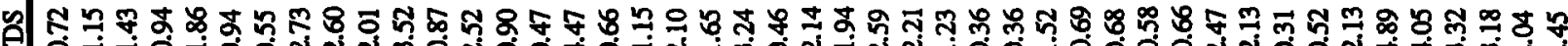

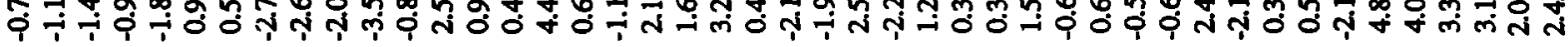

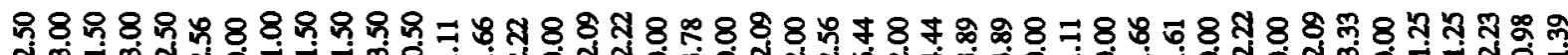

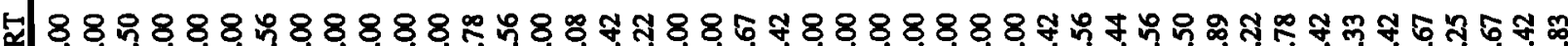
语

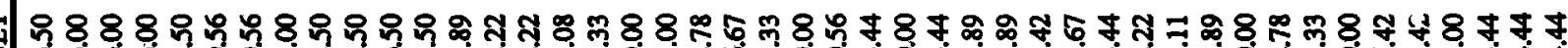

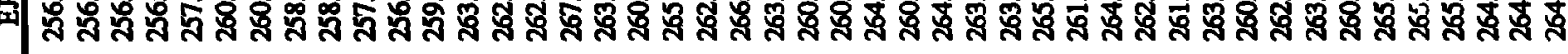

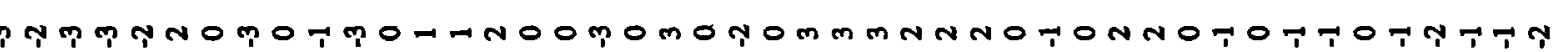

更最

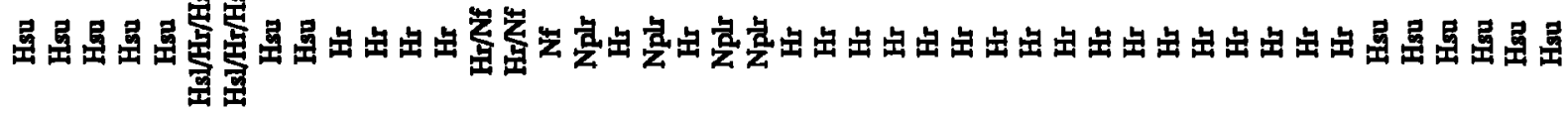

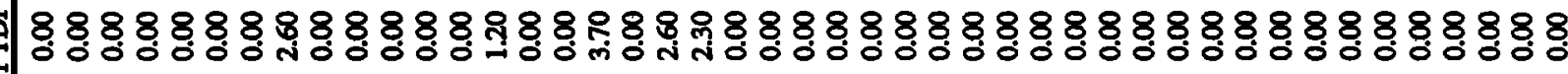

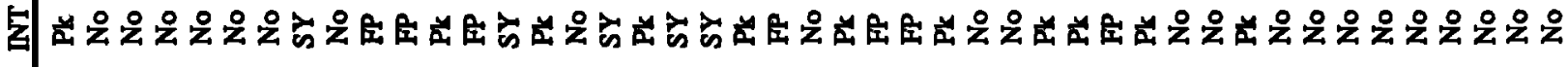

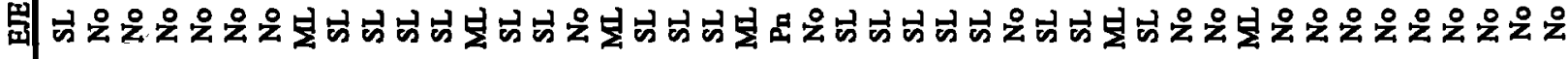

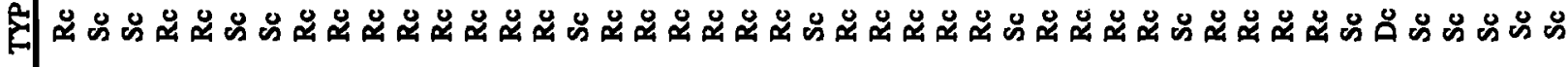

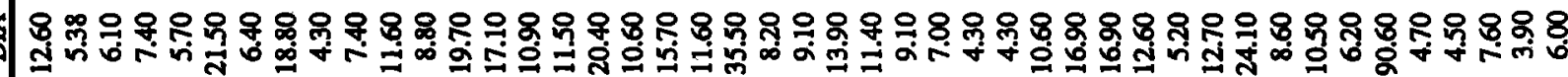

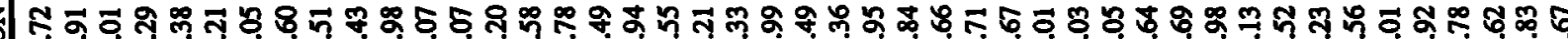
ఐ

북 ㅇำ

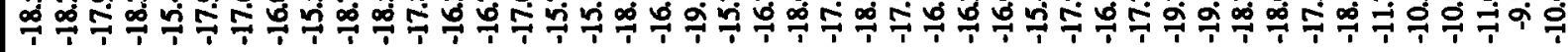

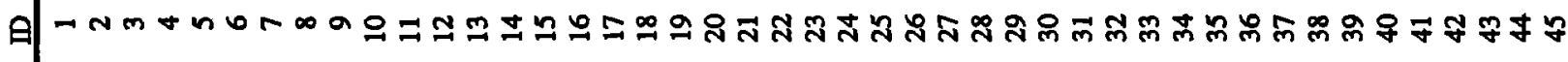


인

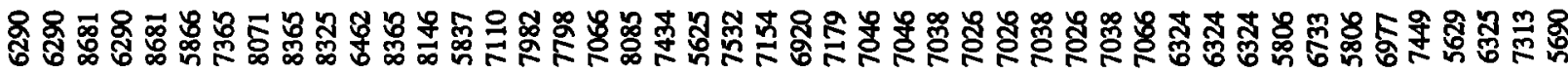

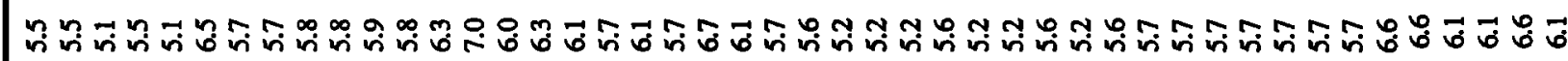
중정 종정 꽁

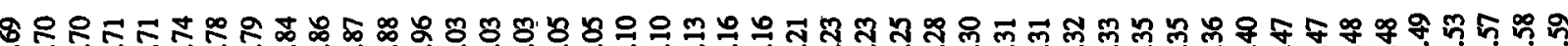

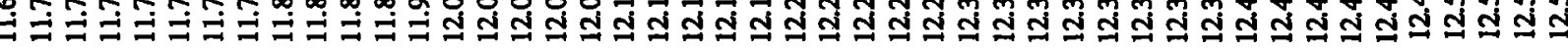

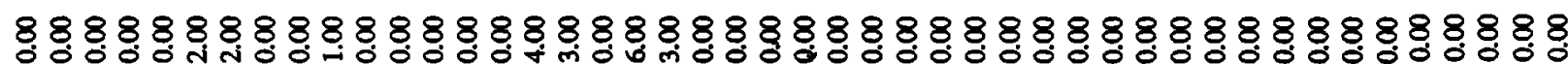

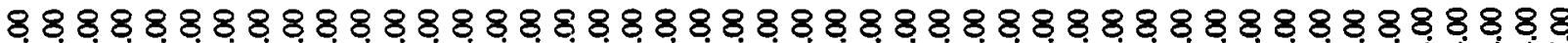

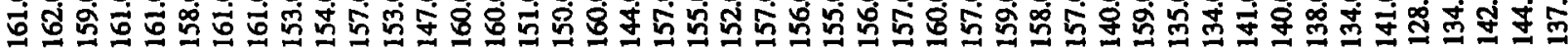

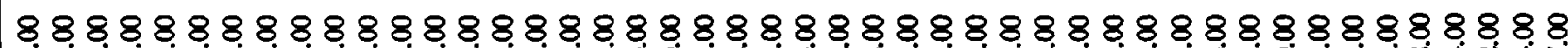

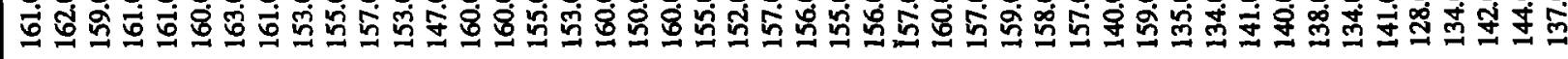
ڤ̆ ஜ

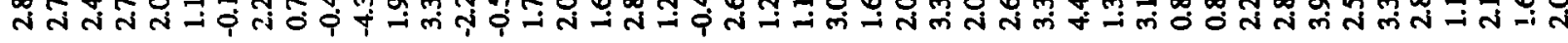

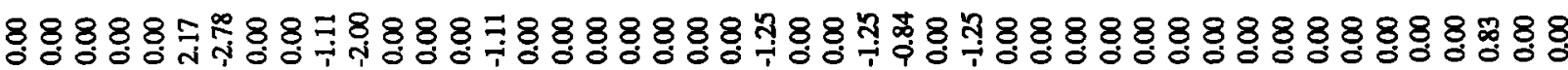
m

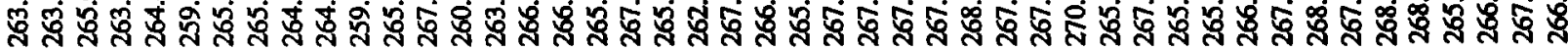

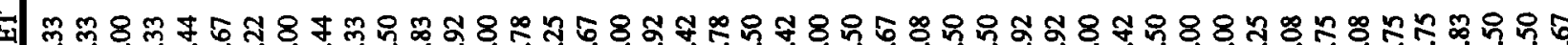

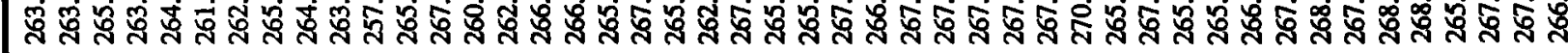

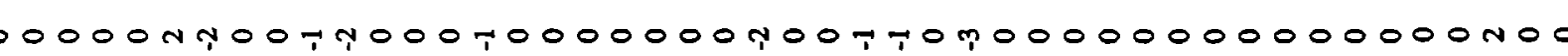

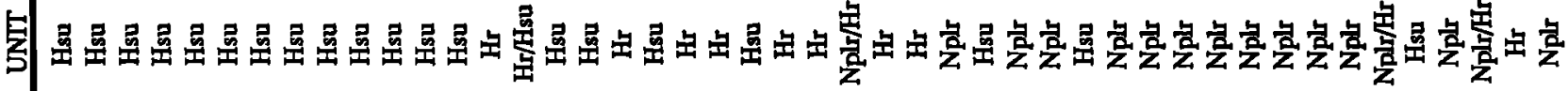

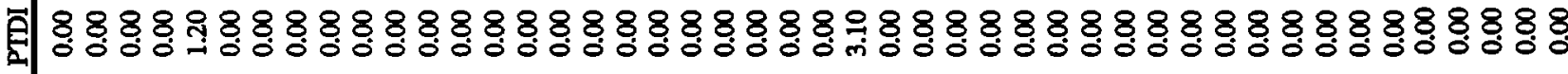

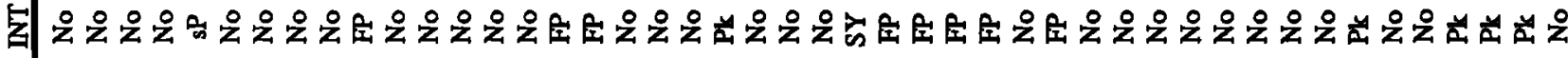

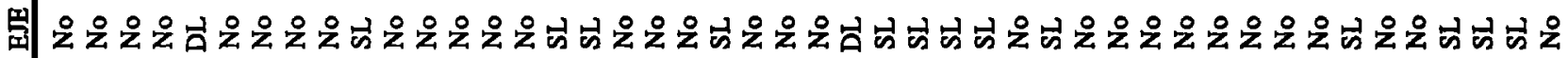

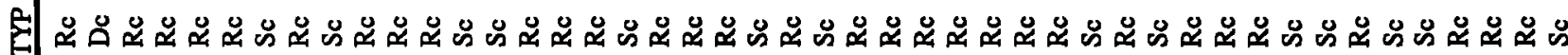

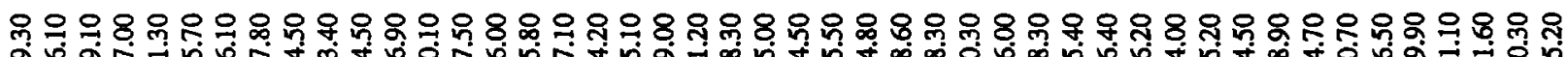

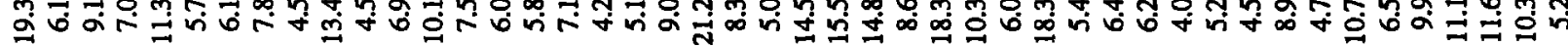

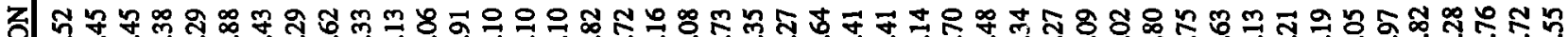

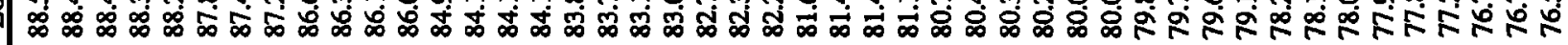

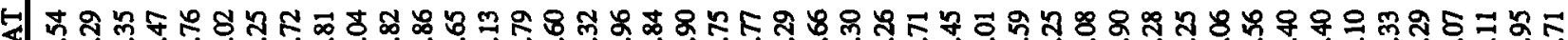

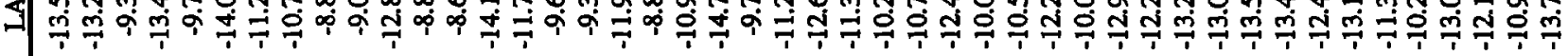

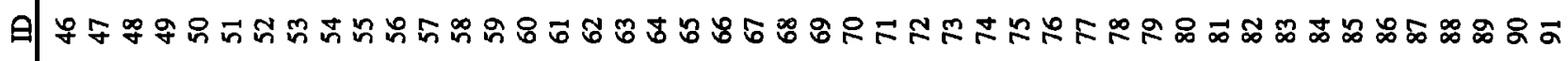




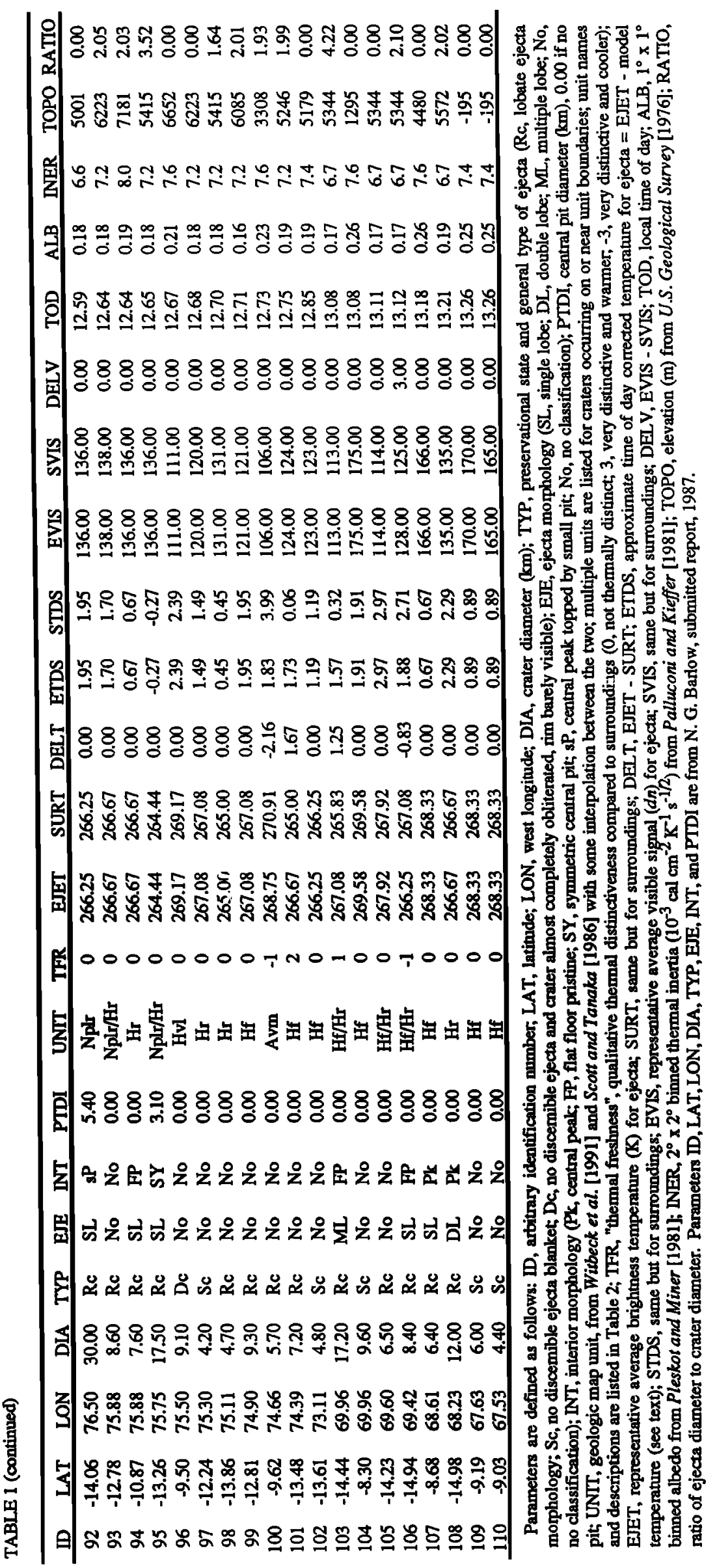


TABLE 2. Description of Geologic Map Units

\begin{tabular}{ll}
\hline Unit & \multicolumn{1}{c}{ Name and Interpretation } \\
\hline Apk & $\begin{array}{l}\text { Knobby plains material-Probably of diverse origins but appears to have formed mainly by erosion of older units. Knobs are probably } \\
\text { erosional remnants but some may be volcanic. Intervening plains may be erosional surfaces or may consist of eolian, mass-wasted, or } \\
\text { volcanic materials. }\end{array}$ \\
Hsu & $\begin{array}{l}\text { Syria Planum formation, Upper member-Lava flows of Syria Planum; erupted from summit area of Syria Planum and from local } \\
\text { fractures. }\end{array}$ \\
Hsl & Syria Planum formation, Lower member-Similar to upper member but more highly cratered and faulted. \\
Hpl 3 & Plateau sequence, Smooth unit-Probably a complex of eolian, volcanic and alluvial materials. \\
Hf & Highly defomed terrain materials, Younger fractured material-Probably lava flows. Faults caused by crustal extension; collapse \\
depressions formed by withdrawal of subsurface water or ice. Modified ridged plains material at Nia Fossae (Note: Nia Fossae is the
\end{tabular}

\section{TerRain DePENDENCIES}

Virtually all of the more than 100 EDITHs seen in the Termoskan data are located on Hesperian age plains that surround much of Valles Marineris. This region was observed in the third of the four Termoskan panoramas with a resolution of about $1.8 \mathrm{~km} /$ pixel. The other three panoramas primarily observed very old (Noachian age) intercrater plains and cratered highland units. Figure 8 shows the coverage of each of the panoramas overlain on a simplified low-resolution geologic map of Mars.

There is a startlingly clear correlation of EDITH existence with terrains of Hesperian age, implying spatial or temporal dependence on Hesperian terrains. This is the strongest correlation between EDITHs and any other parameter. EDITHs are present on all the Hesperian age units observed by Termoskan. As exemplified by Figure 1, almost no EDITHs are associated with any of the thousands of craters within the data set that occur on the older Noachian units, except five EDITHs clustered near a high contrast albedo boundary in Sinus Meridiani. These five may be the consequence of a very distinctive localized aeolian albedo effect, probably unlike most other EDITHs. Thermally distinct ejecta blankets do not appear on the portions of the younger Tharsis Amazonian units seen in the data. Only four clear thermally distinct ejecta blankets are seen in panorama 4 and these occur on Hesperian to Amazonian age lowland material near the highland-lowland boundary (see region 4 in section 6). They also occur infrequently and weakly on Amazonian units within Valles Marineris.

Although more subtle than the Hesperian terrain dependence, there are also terrain dependent correlations on the relatively high elevation Hesperian Syria Planum Upper Member (Hsu) unit, but not on the adjacent Hesperian ridged (Hr) unit. These are the two primary EDITH bearing terrains within our data base. Correlations and observations of EDITHs that occur on Hsu but not on $\mathrm{Hr}$ include the following. (1) All EDITHs on Hsu, with one exception, have ejecta blankets that are cooler than the surroundings. (2) Time of day corrected ejecta temperature shows strong correlation with time of day corrected temperature of the surroundings. The temperature difference (ejecta surroundings) of the Hsu craters varies little (in general less than $2 \mathrm{~K}$ ) even when the absolute temperatures of the surroundings change significantly (approximately $10 \mathrm{~K}$ ). Therefore, ejecta temperature has a consistent dependence upon the surrounding temperature. (3) Time of day corrected ejecta temperature and time of day corrected temperature of the surroundings show some correlations with elevation and latitude. These correlations occur because elevation and latitude in the data base region correlate with inertia, albedo, and each other. Inertias decrease and albedos increase with higher elevation on $\mathrm{Hsu}$, causing higher midday temperatures.

We believe that these correlations, which appear on Hsu but not on $\mathrm{Hr}$, arise from increased dust mantling on the higher elevation Hsu unit, rather than from a bedrock geologic unit variation. Increased dust mantling is consistent with the lower inertias and higher albedos of the Hsu unit. Inertia ranges from 5 to 6 above $6500 \mathrm{~m}$ (elevations that occur primarily on Hsu and range up to $9000 \mathrm{~m}$ ) and from 6 to 8.5 below $6500 \mathrm{~m}$. The Hsu area is near the edge of the Tharsis low inertia region which has been proposed to have a dust covering and to be an area of dust deposition [Kieffer et al., 1977; Zimbelman and Kieffer, 1979; Palluconi and Kieffer, 1981; Christensen, 1986], but still an area with some exposed rocks [Christensen, 1982, 1983]. The high elevation regions within our data base have higher inertia (5 as opposed to 2 or 3 in units of $10^{-3} \mathrm{cal} \mathrm{cm}^{-2} \mathrm{~K}^{-1} \mathrm{~s}^{1 / 2}$ ) than Tharsis; however, the Hsu albedo and inertia still probably imply at least some dust mantling, and more than elsewhere within the data base. It would be difficult for an ejecta related mechanism, either primary or secondary, to cause higher brightness temperatures than already occur on this dust mantled region. An increased thickness of dust mantle on both ejecta and surroundings also would help explain the observed reduced temperature difference between surroundings and ejecta. The ejecta still appear thermally distinct either because of differences 


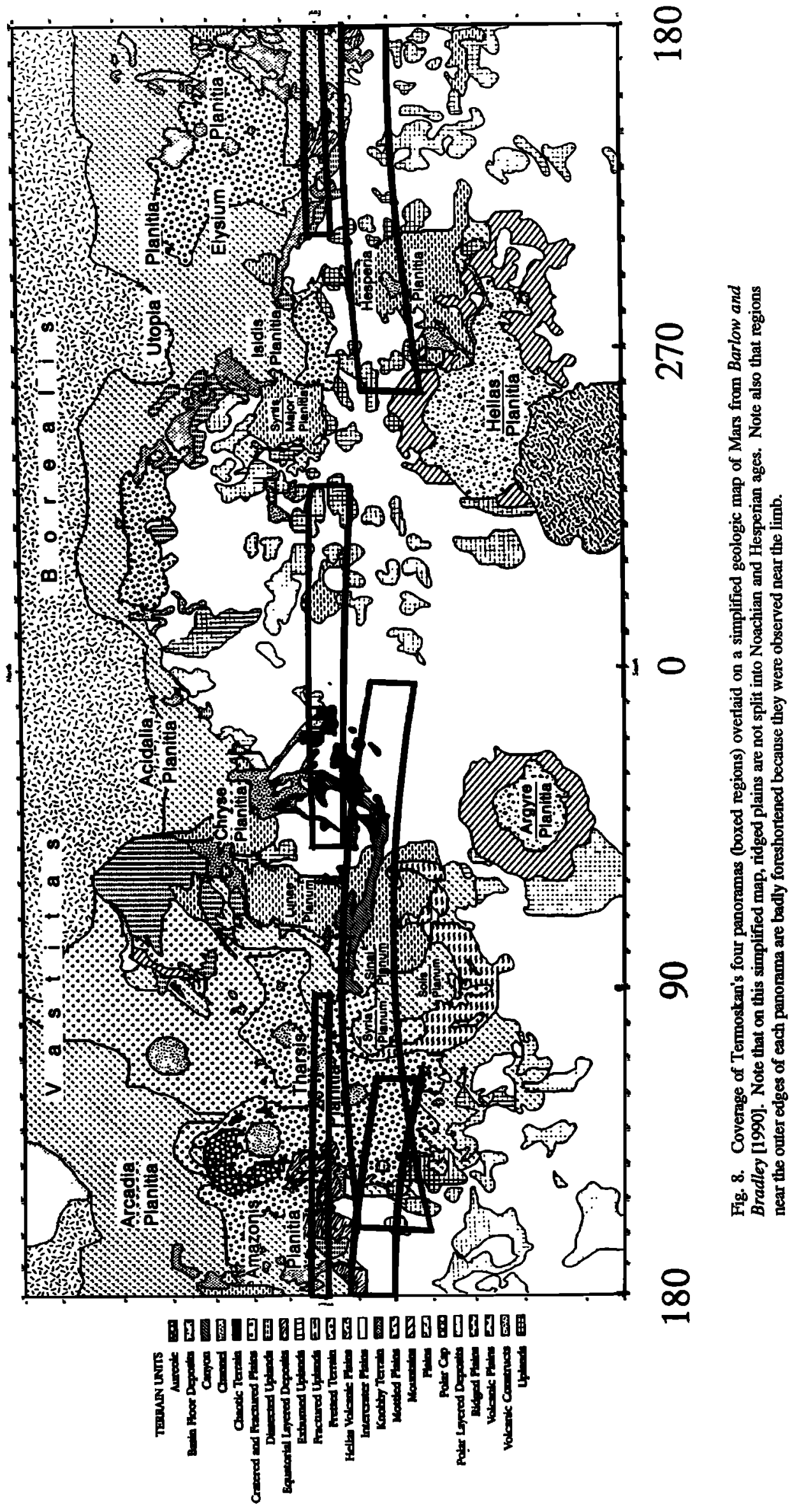


in the blocks poking through the dust layer or thermal differences showing through a thin dust layer.

\section{A LAYERING EXPLANATION}

We postulate that most of the observed EDITHs are due to excavation of thermally distinctive Noachian age material from beneath a relatively thin layer of younger, more consolidated Hesperian volcanic material. The plausibility of this theory is supported by much geological evidence for the EDITH-rich plains units having relatively thin near-surface Hesperian deposits overlying massive Noachian megabreccias. We suggest that absence of thermally distinct ejecta blankets on Noachian and Amazonian terrains is due to absences of distinctive nearsurface layering.

Layering is in general important to determining ejecta blanket characteristics [Oberbeck and Quaide, 1968; Head, 1976; De Hon, 1980; Pike, 1980; Greeley et al., 1982; Horner and Greeley, 1987; Barlow and Bradley, 1990], and thus it would not be surprising if it were also involved with EDITHs. The simplest form of our layering explanation is a two-layer model (see Figure $9 a$ ). The top layer (layer 1 ) is a relatively thin (hundreds of meters) Hesperian age unit consisting primarily of lavas which were probably emplaced as a series of low-viscosity flows. The lower layer (layer 2) is a massive Noachian layer believed to consist of impact breccia.

The majority of EDITHs observed occur on the layered Hesperian plains surrounding Valles Marineris. Indeed, layering in the walls of Valles Marineris, observable in Viking camera images and now also in Termoskan thermal images, is a firstorder observation of layering in this region. In addition, the geologic plausibility of our layered model is supported by many lines of evidence in this region for very few hundred meter thick [De Hon, 1985; Frey and Grant, 1989; Frey and Grant, 1990] Hesperian lavas overlying a mechanically weak, Noachian megaregolith layer (our layer 2) [Tanaka and Chapman, 1992; Davis and Golombek, 1990; Robinson and Tanaka, 1988; MacKinnon and Tanaka, 1989]. An approximate megaregolith thickness of 2 to $3 \mathrm{~km}$ is suggested [Fanale, 1976; Woronow, 1988; MacKinnon and Tanaka, 1989; Soderblom and Wenner, 1978; Davis and Golombek, 1990]. Horner and Greeley [1987] used a two-layer model very similar to ours in this region to explain the increase in crater complexity with decreasing thickness of the $\mathrm{Hr}$ unit. They proposed that some property of the lower layer (e.g., increased fracturing during impact or increased volatile content) caused the greater complexity. Likewise, we propose that some physical property of our lower layer causes thermally distinct ejecta blankets.

How does material from layer 2 end up on the surface of an ejecta blanket? Ballistic ejection will invert stratigraphy near the rim of the crater [Roddy, 1977; Stoffler et al., 1975] and cover most of the blanket further out with shallow derived material [Horz et al., 1983]. Thus, a sufficiently large impact will cause layer 2 material to overlie layer 1 material near the $\mathrm{rim}$ of the crater. Preliminary modeling (B. Ivanov, personal communication, 1992) of fluidized ejecta blanket emplacement on Mars suggests that the layer 2 material may then flow over much of the rest of the ejecta blanket (sce Figure $9 b$ ).

EDITHs may directly be the result of inertia and/or albedo differences between layer 2 ejecta material and the surrounding layer 1 material. For example, either pumicelike blocks or very fragmented material from layer 2 could cause the ejecta blanket to have a lower inertia than the layer 1 surroundings. Alternatively, current thermal differences may result from secondary processes such as aeolian deposition or some kind of alteration preferentially acting upon the layer 2 surface. These processes may alter thermal inertia or albedo. In any case, we propose that some property of the layer 2 (Noachian) material causes the eventual thermal contrast with the layer 1 (Hesperian) surroundings.

We attribute the absence of EDITHs on the majority of Noachian and Amazonian terrains to a lack of distinctive near surface layering. Noachian terrains would have layer 2 type material on the surface before a given impact. Thus, the impact would eject material that is sufficiently similar to the surroundings that over time they will be thermally indistinguishable.

The observed absence of EDITHs on the majority of Amazonian units is probably due to the thickness of the terrains which happened to be observed. Most of the Amazonian units observed by Termoskan are central Tharsis volcanics in the Arsia Mons region. Assuming at least a 2 to $3 \mathrm{~km}$ thickness for this region [Plescia and Saunders, 1980], the small-diameter Amazonian crater population probably would not have excavated any of the material (possible megaregolith) underlying the Tharsis lavas. Instead these impacts likely excavated only lava materially, physically, and thermally similar to the lava already at the surface.

We note that more than two layers may sometimes play a role in EDITH formation, particularly albedo layers, as hinted at by the occurrence of different albedo layers in some Kasei Valles locations [Baker and Milton, 1974; Scott, 1991], although not in others [Tanaka and Chapman, 1992]. In any case, we find that a layering hypothesis is geologically plausible and explains the vast majority of EDITHs (though a few percent require more complex explanations). In the next section we evaluate some localized regions in light of this theory.

\section{INTERPRETATION OF LOCALIZED REGIONS OF STUDY}

We studied four localized regions in greater detail. Figure 4 shows and describes region 1 , which includes four craters near the south rim of an old filled crater and three craters to the northeast of the old crater. The following explanation of the thermal observations is consistent with our overall layering theory. Impacts outside the larger filled crater formed ejecta

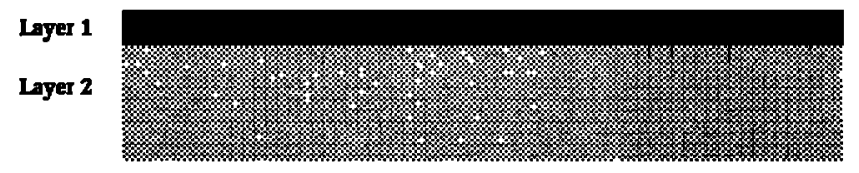

(a)

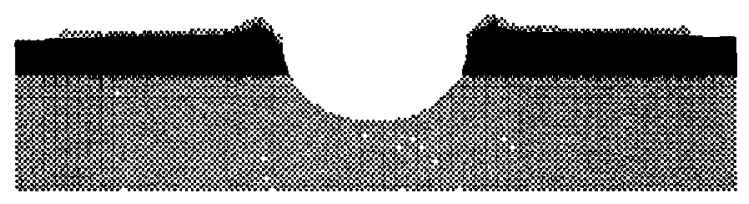

(b)

Fig. 9. (a) Schematic of our layering model before impact. Layer 1 is a relatively thin layer of consolidated Hesperian lavas. Layer 2 is comprised of massive Noachian megabreccia. (b) Postimpact view of a fluidized lobate EDITH. Vertical relief of the ejecta blanket is exaggerated. Note the layer 2 material through ballistic ejection and fluidized flow has covered most of the layer 1 ejecta material and contrasts themally with the layer 1 surroundings. 
blanket surfaces from (layer 2) Noachian material that originated in undisturbed layers beneath a thin layer of Hesperian cover. Due to a presumably thicker Hesperian layer filling the old crater, the impacts inside the old crater rim ejected less of the layer 2 material. Thus, these ejecta blankets are cooler than the blankets outside the old rim, but still distinct and warmer than their surroundings. In this interpretation, the layer 2 material has lower albedo. The old crater rim material and the Noachian material to the northwest may be made of the same layer 2 material.

For this region alone, we could not rule out an alternate theory of preferential trapping of secondary aeolian material due to localized roughness. Darker aeolian material could have been preferentially trapped by the ejecta blankets, crater rim, and Noachian material due to increased roughness. The blankets inside the crater rim may be different because less of the material that is being preferentially trapped by the rim makes it past the rim. Alternatively, the blankets inside the old rim may have a different degree of roughness than those outside the crater rim. Roughness differences could, however, primarily depend on the excavation of a different lower layer. Preexisting or impact induced roughness may also have caused the wide thermal anomaly associated with the crater to the $\mathrm{NE}$ of the large filled crater; however, the exact cause of the extent of this anomaly remains unclear.

Our second localized region of study includes several nearby craters, one with a thermally distinct ejecta blanket and the other seven without. Of particular interest are the two largest nearby craters. The larger has thermally distinct ejecta (labeled crater A in Figure 5), the other does not (crater B in Figure 5). Degree of freshness does not seem to explain the thermal differences. We infer that the largest crater $(11.6 \mathrm{~km})$ was the only one in this region that excavated deep enough to reach a physically different layer beneath the Hesperian surface layer. The juxtaposition of these and other similar EDITH/non-EDITH crater pairs (see also region 3 below) implies that neither local wind patterns nor local availability of aeolian material is sufficient on their own to explain EDTTH observations.

Our third localized region of study (Figure 6) is an area on the north rim of Valles Marineris where there are three nearby craters of roughly similar sizes $(9.8 \mathrm{~km}, 10.5 \mathrm{~km}$, and $5.8 \mathrm{~km})$. The largest and "middle" crater is the only one of the three that does not have a thermally distinct ejecta blanket. Thus, excavation of a single lower layer is not alone a sufficient explanation. The middle crater shows the least fresh (presumably oldest) ejecta blanket. Erosional or depositional effects probably removed any thermal distinctiveness.

Our fourth region of study involves the only four clear EDITHs in panorama 4 (see Figure 7). All of the EDITHs lie on lowland terrains very near the highland-lowland boundary. Two EDITHs (labeled 1 and 2) are situated on a small exposure of $\mathrm{Hpl}_{3}$, a smooth Hesperian unit (see Table 2 for unit descriptions). Based upon exposed rims of buried craters, this unit is thin (a very few hundreds of meters). It is embayed primarily by older Noachian (highland) material (unit $\mathrm{Npl}_{1}$ ), implying that the thin Hesperian layering overlies the Noachian unit. Craters 3 and 4 lie on Hesperian and Amazonian terrain near the boundary with the $\mathrm{Npl}_{1}$ unit. Thus, these four EDITHs are consistent with our layering theory, excavating materially different Noachian material from beneath a thin younger (Hesperian or Amazonian) cover. EDITHs are not observed further from the highlandlowland boundary presumably because of an increasing thickness of Amazonian deposits. Note that EDITH number 4 is somewhat anomalous relative to most EDITHs. Most EDITHs that are cooler than surroundings are visibly brighter or not visibly distinct. In contrast, EDITH number 4 is both cooler and visibly darker than the surroundings. Thus (because of the near midday conditions) this EDITH definitely has a higher inertia than the surroundings.

\section{ALTERNATE EDITH HYPOTHESES}

Next, we critique several alternatives to our layering theory and show that most of them are unable to explain adequately the presence of EDITHs.

The Hesperian terrain dependence of EDITHs cannot be explained by either atmospheric or impactor conditions. Noachian and Hesperian terrains must have experienced identical atmospheric and impactor conditions during Hesperian times. In addition, the absence of correlations with elevation within the entire data base suggests that EDITH variations are not the result of elevation dependent atmospheric pressure variations. EDITHs must therefore be dependent upon target material and/or distinctive secondary modification of Hesperian terrains.

One possible significant target material property is variation in volatiles. Subsurface volatiles are thought to influence formation of lobate ejecta blankets. The Noachian terrains in our study region near Valles Marineris exhibit similar percentages and morphologies of lobate blankets as the Hesperian units. Also, lobate blankets appear on many of the Noachian terrains seen elsewhere within the Termoskan data. Thus, neither the presence nor the variability of lobate blankets explains the Hesperian EDITH correlation. The ratio of ejecta diameter to crater diameter is thought by several authors to be a measure of the amount of volatiles in the original target material [e.g., Mouginis-Mark, 1979; Kuzmin et al., 1988]. Thus, the absence of correlations with this ratio may indicate that neither the degree of fluidization, nor the amount of original volatiles play major roles in EDITH variability. Central pits are also thought by some to be related to volatiles in the target material [Rossbacher and Judson, 1981], yet there are no correlations between central pits and EDITHs.

Crater diameter is thought to be correlated with depth of excavation. Thus, the lack of correlations with crater size indicates that excavations of different material underlying a surface layer of uniform thickness cannot alone explain EDITH variations. However, this does not preclude a variable thickness layered theory, which is more realistic for this region anyway [e.g., De Hon, 1985], nor one that introduces secondary effects such as age.

Certain processes are inadequate to explain overall EDITH variations but may be secondary influences. For example, proximity of EDITH/non-EDITH pairs (e.g., region 2 and region 3) rules out local wind patterns and local availability of aeolian material as first-order effects, though not necessarily as secondorder effects. Another example is ejecta freshness (age related alteration) which is similarly unsatisfactory as an overall explanation. Many degrees of freshness (as determined by sharpness and distinctiveness in Viking camera images) are observed on Noachian terrains which do not have EDITHs. Even on Hesperian terrains alone, freshness seems incapable of explaining all observations (e.g., region 2). Freshness does, however, probably function as an important second-order influence (e.g., regions 1 and 3).

Variations in maturity of a duricrust (i.e., degree of bonding of a case-hardened crust) were suggested by Jakosky and Christensen [1986] to explain most of the low-resolution thermal 
inertia variations on Mars. Duricrust variations are not, however, adequate for explaining the higher resolution EDITHs for the following reasons. First, there is no reason duricrust formation should be related to albedo as some EDITHs are. Second, one would expect younger, and thus less mature, ejecta duricrusts to have lower inertia than their surroundings. However, both lower and higher inertia EDITHs are observed. Third, Jakosky and Christensen's proposed time scale for duricrust formation (105 $-10^{6}$ years) is too short to explain EDITHs.

Physical change in ejecta material due to the impact process cannot explain Hesperian EDITH variations for two reasons. First, EDITHs are not associated with all ejecta blankets. Second, there is no correlation of EDITHs with impact energy as evidenced by crater sizes. However, preferential physical change in some ejecta material due to impact could result from layering. If one layer, when impacted, metamorphoses or welds more easily than another layer, this difference between layers may manifest itself as a long-term thermal inertia difference.

One alternate hypothesis that we considered thoroughly and did not rule out entirely presumes the Hesperian plains to be smoother than the Noachian plains at a (small) scale important to clastic particle trapping. They appear this way at Viking camera resolutions (of order $100 \mathrm{~m}$ on average). The increased Noachian roughness may be due to some age-related factor, such as impact brecciation or other alteration processes. If this is the case, aeolian particles may saltate across the smooth Hesperian units, only being trapped upon rough areas such as ejecta blankets. In contrast, the rougher Noachian terrain may trap saltating material everywhere, not just on ejecta blankets. There are various difficulties with this hypothesis. To explain EDITHs near nonEDITHs, this theory must rely more heavily than a layering theory on factors such as freshness of ejecta blankets. Also, this theory does not have the layering advantage for explaining the lack of EDITHs on thick Amazonian terrains or the occurrence of Amazonian EDITHs only near the highland-lowland boundary. Presuming that the Amazonian terrains are also rougher than the Hesperian terrains is inconsistent with Viking imaging resolution observations and with age correlated roughness development.

A second alternate hypothesis we considered seriously is that the Noachian unit intrinsically has more material available for local redeposition. Barlow [1990] finds that erosion on Mars decreased drastically at the end of the Noachian period, and has probably remained relatively constant at very low rates since that time. Hesperian terrains probably experienced little erosion. In contrast, erosion on Noachian terrains during the Noachian period may have produced ubiquitous sand sized particles. These particles were then available via saltation and creep to blanket ejecta and obscure its thermal signature over time. The Hesperian terrains may look more like Viking Lander sites, i.e., not exhibiting a true regolith, whereas the Noachian terrain may better resemble a true regolith, similar to the lunar surface. Like the Noachian roughness hypothesis discussed above, the Noachian redepositional material hypothesis also has difficulties explaining the lack of EDITHs on Amazonian units. Amazonian terrains should have less erosional products and less developed regolith than Hesperian terrains. Thus, although we cannot firmly rule out either of these last two alternate hypotheses, we believe they are much less plausible than our layering hypothesis.

\section{Conclusions}

In conclusion, we postulate that EDITHs exist on Hesperian units near Valles Marineris because of impact excavation into a thick, more fragmented, materially different Noachian layer beneath a relatively thin layer or layers of Hesperian volcanic material. We also postulate that EDITH variations are primarily controlled by the degree of excavation of the Noachian layer. However, secondary effects such as degree of erosion of the blankets or local availability of aeolian material probably cause some thermal variations. The thermally distinct nature of the blankets probably results from the ejecta itself, or possibly from secondary aeolian deposits preferentially trapped on the blankets. Our layering theory predicts that EDITHs will not generally occur at small crater sizes except where very thin layering exists.

The importance that a brecciated layer has for EDITHs leads to speculation whether this layer is also important for explaining the uniquely Martian phenomenon of fluidized ejecta blankets. Brecciated material will flow more easily than nonbrecciated material. In addition, the breccias' porosity and their origin in what may have been more water-rich Noachian times could have led to ice presence (as suggested by Tanaka and Chapman [1992]). The possible importance of such a Noachian brecciated layer to explaining why fluidized ejecta blankets occur so frequently on Mars and so rarely on other bodies is the subject of work in progress.

\section{Future Missions/Research}

EDITHs must be relatively mantle free and exhibit material ejected from depth. Thus, the surfaces of EDITHs are attractive sites for refined observations because these relatively pristine surfaces may offer important clues to understanding fluidized ejecta blankets, the Martian subsurface, and subsurface volatiles. Mars Observer (MO) will provide an opportunity to observe ejecta blankets on Mars in greater detail with the thermal emission spectrometer (TES), the pressure modulated infrared radiometer (PMIRR), the Mars Observer camera (MOC), and the Mars Observer laser altimeter (MOLA).

TES will have similar resolution ( $3 \mathrm{~km} / \mathrm{pixel}$ ) to the Termoskan panoramas used in our analyses, but greater sensitivity and medium resolution infrared emission spectroscopy. TES will facilitate expansion of our EDITH analysis in many ways: testing whether EDITH terrain dependencies hold on a global scale, providing much greater diurnal and seasonal coverage, providing accurate determination of the relative importance of inertia versus albedo for EDITHs, and allowing us to look for spectroscopic differences between ejecta and surroundings. In addition, TES's spectroscopic measurements can check for increased minerals of hydration that might be expected from volatile-rich emplacement mechanisms.

Using methods similar to those used by Christensen [1982, 1983], TES data will also facilitate looking for variations in percentage of rocks and fine component inertia between ejecta blankets and surroundings, between different ejecta blankets, and within each ejecta blanket. Results should indicate whether variations in the fine component inertia or the percentage of blocks are more responsible for the EDITH variations observed. In addition, preferential trapping of certain sized particles can be tested by looking at variations in fine component inertias. Also, if albedo, block percentages, or fine component inertia are seen to vary with time, then we will be led towards aeolian processes contributing to EDITH variations.

PMIRR, with somewhat worse spatial resolution than TES, will standardly take nadir thermal observations and obtain surface temperatures, albedos, and inertias. PMIRR will, however, have detailed simultaneous atmospheric information different from that obtained by TES, which will aid in atmospheric corrections to albedo and inertia. 
MOC's maximum resolution of 1.4 meters/pixel resolution will facilitate the best ever study of ejecta blanket surface detail and horizontal structure. Study of EDITHs will ensure study of more pristine ejecta blanket surfaces. MOC will be able to detect block albedo differences between ejecta and surroundings for very large blocks. MOC observations of EDTHS also may help to test the role of volatiles in the fluidized ejecta emplacement mechanism. Observed presence of devolatilization features would imply that volatiles were important in the fluidized ejecta emplacement mechanism [Mouginis-Mark, 1987]. MOC data will also constrain the mechanics of fluidized ejecta flow by showing in detail possible flow-related surface features such as striations, ridges, and the size distribution of large boulders.

MOLA profiles, with a vertical precision of about $2 \mathrm{~m}$ and horizontal resolution of $165 \mathrm{~m}$, will provide detailed vertical structural information about EDITHs. Such profile information will be very important for constraining mechanical models of fluidized ejecta flow. In addition, signal shape will give information about the small scale surface roughness of the blankets.

Termoskan 2 planned for Mars 94 is expected to increase spatial resolution another order of magnitude from most of the Termoskan 1 data. The high spatial resolution will enable study of more small craters to test the prediction that these small craters should not have EDITHs except on very thin Hesperian or possibly Amazonian units.

Finally, we note that EDITHs also may be excellent targets for future landers because EDITHs are not significantly mantled, and material ejected from depth is exposed at the surface.

Acknowledgments. We thank Kenneth Tanaka, David Paige, and William Anderson for timely and thoughtful comments on early versions of the manuscript and Jeff Plescia and Peter Mouginis-Mark for their detailed reviews of our submitted manuscript. We thank Nadine Barlow for providing us with her Catalog of Large Martian Impact Craters, and Amold Selivanov and Margarita Naraeva for assistanco with the Termoskan data set. Funding for this research was provided by NASA grants NAGW1426 and NAGW-2491. Division of Geological and Planetary Sciences, Califomia Institute of Technology contribution 5108.

\section{REFERENCES}

Arvidson, R.E.M., M. Coradini, A. Carusi, A. Coradini, M. Fulchignomi, C. Federico, R. Funiciello, and M. Salomone, Latimdinal variation of wind erosion of crater ejecta deposits on Mars, Icarus, 27, 503-515, 1976.

Baker, V. R., and D. J. Milton, Erosion by catastrophic floods on Mars and Earth, Icarus, 23, 27-41, 1974.

Barlow, N. G., Constraints on early events in Martian history as derived from the cratering record, J. Geophys. Res., 95, 14,191-14,201, 1990.

Barlow, N.G. and T.L. Bradley, Martian impact craters: Correlations of ejecta and interior morphologies with diameter, latitude, and termin, Icarus, 87, 156-179, 1990.

Betts, B. H., Themal and visible studies of Mars using the Termoskan data set, Ph.D. thesis, Calif. Inst. of Technol., Pasadena, 1993.

Carr, M.H., L.S. Crumpler, J.A. Cutts, R. Greeley, J.E. Guest, and H. Masursky, Martian impact craters and emplacement of ejecta by surface flow, J. Geophys. Res., 82, 4055-4065, 1977.

Christensen, P. R. Martian dust mantling and surface composition: Interpretation of thermophysical properties, J. Geophys. Res., 87, 99859998, 1982.

Christensen, P. R., The distribution of rocks on Mars (abstract), Lunar Planet. Sci., XIV, 109-110, 1983.

Christensen, P. R., Regional dust deposits on Mars: Physical properties and global distribution, J. Geophys. Res., 91, 3534-3546, 1986.

Clifford, S. M., and E. Duxbury, Sub-kilometer rampart craters in the equatorial region of Mars: Possible implications for the state and distribution of regolith $\mathrm{H}_{2} \mathrm{O}, \mathrm{MEVTV}$ Workshop on Nature and Composition of Surface Units on Mars, edited by J.R. Zimbelman, S.C. Soloman, and V. L. Sharpton, LPI Tech. Rep. 88-05, pp. 44-45, Lunar and Planet. Inst., Houston, Texas, 1988.
Clifford, S.M. C.J. Bartels, and E.P. Rubenstein, The Mars thermal model (MARSTHERM): A FORTRAN 77 finite-difference program designed for general distribution, Lunar and Planet, Inst., Houston, Texas, 1987.

Davis, P. A., and M. P. Golombek, Discontinuities in the shallow Martian crust at Lunae, Syria, and Sinai Plana, J. Geophys. Res., 95 (B9), 14,231$14,248,1990$.

De Hon, R. A., Variations in interior morphology of $15-20 \mathrm{~km}$ lunar craters: Implications for a major subsurface discontinuity, Proc. Lunar Planet. Sci. Conf., 11th, 2207-2219, 1980.

De Hon, R. A., Ridged plains of Lunae Planum: Thickness distribution revised (abstract), Lunar Planet. Sci., XVI, 171-172, 1985.

Fanale, F. P., Martian volatiles: Their degassing history and geochemical fate, Icarus, 28, 179-202, 1976.

Frey, H. V., and T. D. Grant, Resurfacing in Coprates and thickness of the ridged plains (abstract), Lunar Planet. Sci., XX, 313-314, 1989.

Frey, H. V., and T. D. Grant, Resurfacing history of Tempe Terra and surroundings, J. Geophys. Res., 95, 14,249-14,263, 1990.

Gault, D.E., and R. Greeley, Exploratory experiments of impact craters formed in viscous-liquid targets: Analog for Martian rampart craters?, Icarus, 34, 486-495, 1978.

Greeley, R, and J. E. Guest, 1:15M Geologic map of the eastem equatorial region of Mars, U.S. Geol. Surv. Misc. Invest. Map, I-1802-B, 1987.

Groeley, R., J. Fink, D.E. Gault, D.B. Snyder, J.E. Guest, and P.H. Schultz, Impact cratering in viscous targets: Laboratory experiments, Proc. Lunar Planet. Sci. Conf., 1lth, 2075-2097, 1980.

Greeley, R., J. H. Fink, D. E. Gault, and J. E. Guest, Experimental simulation of impact cratering on icy satellites, in The Satellites of Jupiter. edited by D. Momison, pp. 340-378, University of Arizona Press, Tucson, 1982.

Head, J. W., The significance of substrate characteristics in determining morphology and morphometry of lunar craters, Proc. Lunar Sci. Conf., 7th, 2913-2929, 1976.

Homer, V. M., and N. G. Barlow, Martian craters: Changes in the diameter range for ejecta flujdization with latitude (abstract), Lunar Planet. Sci., $X I X, 505-506,1988$.

Homer, V. M., and R. Greeley, Effects of elevation and ridged plains thicknesses on Martian crater ejecta morphology, Proc. Lunar Planet. Sci. Conf. 17th, Part 2, J. Geophys. Res., 92, E561-E569, 1987.

Horz, F., R. Ostertag, and D. A. Rainey, Bunte breccia of the Ries: Continuous deposits of large impact craters, Rev. Geophys., 21, 1667. $1725,1983$.

Jakosky, B. M., and P. R. Christensen, Global duricrust on Mars: Analysis of remoto-sensing data, J. Geophys. Res., 91, 3547-3559, 1986.

Kieffer, H.H., T.Z. Martin, A.R. Peterfreund, B.M. Jakosky, E.D. Miner, and F.D. Palluconi, Thermal and albedo mapping of Mars during the Viking primary mission, J. Geophys. Res., 82, 4249-4291, 1977.

Kuzmin, R.O., N.N. Bobina, EV. Zabalueva, and V.P. Shashkina, Mars: Estimation of the relative thickness of the relative ice content in upper layers of the permafrost (abstract), Lunar Planet. Sci., XIX, 657-658, 1988.

MacKinnon, D. J., and K. L. Tanakn, The impected Martian crust: Structure, hydrology, and some geologic implications, J. Geophys. Res., 94(B12), 17,359-17,370, 1989.

MoCauley, J.F., Mariner 9 evidence for wind erosion in the equatorial and mid-latitude regions of Mars, J. Geophys. Res., 78, 4123-4137, 1973.

Mouginis-Mark, P.J., Martian fluidized crater morphology: Variations with crater size, latitude, altitude, and tanget material, J. Geophys. Res., 84(B14), 8011-8022, 1979.

Mouginis-Mark, P.J., Water or ice in the Martian regolith?: Clues from mampart craters seen at very high resolution, Icarus, 71, 268-286, 1987.

Murray, B. C., et al., Preliminary assessment of Termoskan observations of Mars, Planet.. Space Sci., 39(1/2), 237-265, 1991.

Oberbeck, V. R., and W. L. Quaide, Genetic implications of lunar regolith thickness variations, Icarus, 9, 446-465, 1968.

Palluconi, F. D., and H. H. Kieffer, Themal inertia mapping of Mars from $60^{\circ} \mathrm{S}$ to $60^{\circ} \mathrm{N}$, Icarus, 45, 415-426, 1981.

Pike, R. J., Control of crater morphology by gravity and target type: Mars, Earth, Moon, Proc. Lunar Planet. Sci. Conf., 11th, 2159-2189, 1980.

Plescin, J. B., and R. S. Saunders, Estimation of the thickness of the Tharsis lava flows and implications for the nature of the topography of the Tharsis platean, Proc. Lunar Planet. Sci. Conf., 11th, 2423-2436, 1980.

Pleskot, L. K., and E. D. Miner, Time variability of Martian bolometric albedo, Icarus, 45, 179-201, 1981.

Robinson, M. S., and K. L. Tanaka, Stratigraphy of the Kasei Valles region, Mars, MEVTV Workshop on Nature and Composition of Surface Units on Mars, edited by J. R. Zimbelman, S. C. Solomon, and V. L. Sharpton, LPI 
Tech. Rep. 88-05, pp. 106-108, Lonar and Planet. Inst. Houston, Texas, 1988.

Roddy, D. J., Large-scale impact and explosion craters: Comparisons of morphological and structural analogs, in Impact and Explosion Cratering, edited by D. J. Roddy, R. O. Pepin, and R. B. Merrill, pp. 185246, Pergamon, New York, 1977.

Rossbacher, L. A, and S. Judson, Ground ice on Mars: Inventory, distribution, and resulhing landforms, Icarus, 45, 39-59, 1981.

Schultz, P. H. and D.E. Gault, Atmospheric effects on Martian ejecta emplacement, J. Geophys. Res., 84, 7669-7687, 1979.

Schultz, P. H., and D.E. Gault, On the formation of contiguous ramparts around Martian impact craters (abstract), Lunar Planet. Sci., XV, 732-733, 1984.

Scoth D. H., Geologic map of MTM quadrangles 25057 and 25052, Kasei Valles region of Mars, US. Geol. Surv. Misc. Invest. Ser. Map, I-2208, scale 1:500,000, 1991.

Scott, D. H. and Tanake, K. L., Geologic map of the westem equatorial region of Mars, US. Geol. Surv. Misc. Invest. Ser. Map, I-1802A, scale 1:15,000,000, 1986.

Selivanov, A. S., M. K. Naraeva, A. S. Panfilov, Yu. M. Geldin, V. D. Khartamov, A. V. Romanov, D. A. Fomin, and $Y_{2}$. Ya. Miroshnichenko, Thermal imaging of the surface of Mars, Nature, 341, 593-595, 1989.

Shoemaker, E. M., Interpretation of lunar craters, in Physics and Astronomy of the Moon, edited by Z. Kopal, Pp. 283-360, Academic, San Diego, Calif., 1962.

Shorthill, R. W., The infrared moon: A review, in Lunar Thermal Characteristics, Progr. Aeronaut. Astronaut. Ser., edited by J. Lucas, MIT Press, Cambridge, Mass., 1972.

Soderblom, L. A., and D. B. Wenner, Possible fossil $\mathrm{H}_{2} \mathrm{O}$ liquid-ice interfaces in the Martian crust, Icarus, 34, 622-637, 1978.

Stoffler, D., D. E. Gault, J. Wedekind, and G. Polkowski, Experimental hypervelocity impact into quartz sand: Distribution and shock metsmorphism of ojecta, J. Geophys. Res., 80, 4062-4077, 1975.

Strom, R. G., S. K. Croft, and N. G. Barlow, The Martian impact cratering record, in Mars, edited by H. H. Kieffer, B. M. Jakosky, C W. Snyder, and M. S. Matthews, pp. 383-423, University of Arizona Press, Tucson, 1992.

Tanskn, K. L., and M. O. Chapman, Kasei Valles, Mars: Interpretation of canyon materials and flood sources, Proc. Lunar Planet. Sci. Conf., 22nd, 1992.

U.S. Geological Survey, Topographic map of Mars, US. Geol. Surv. Misc. Invest. Ser. Map, 1-961, 1976. (Reproduced in the Mars Consortium data set.)

Witbeck, N. E., K. L. Tanaka, and D. H. Scott, Geologic map of the Valles Marineris region (east and west halves), Mars, US. Geol. Surv. Misc. Invest. Ser. Map, I-2010, scale 1:2,000,000, 1991.

Wornow, A., Variation in thickness of ejecta cover on Mars with increasing crater deasity, MEVTV Workshop on Nature and Composition of Surface Units on Mars, edited by J. R. Zimbelman, S. C. Solomon, and V. L. Shapton, LPI Tech. Rep. 88-05, pp. 135-137, Lunar and Planet. Inst., Houston, Texas, 1988.

Zimbelman, J. R., and H. H. Kieffer, Thermal mapping of the northem equatorial and tempenate latitudes of Mars, J. Geophys. Res., 84, 8239$8251,1979$.

B. H. Betts and B. C. Murray, Planetary Science 170-25, Califomia Institute of Technology, Pasadena, CA 91125.

(Received January 29, 1992;

revised November 11, 1992;

accepted January 12, 1993.) 